\title{
Review Article \\ Review of Response and Damage of Linear and Nonlinear Systems under Multiaxial Vibration
}

\author{
Ed Habtour, ${ }^{1}$ William (Skip) Connon, ${ }^{2}$ Michael F. Pohland, ${ }^{3}$ Samuel C. Stanton, ${ }^{4}$ \\ Mark Paulus, ${ }^{5}$ and Abhijit Dasgupta ${ }^{6}$ \\ ${ }^{1}$ Vehicle Technology Directorate, US Army Research Laboratory, APG, MD 21005, USA \\ ${ }^{2}$ US Army Aberdeen Test and Center (ATC), APG, MD 21005, USA \\ ${ }^{3}$ US Army Materiel System Activity Analysis (AMSAA), APG, MD 21005, USA \\ ${ }^{4}$ US Army Research Office, Durham, NC 27709, USA \\ ${ }^{5}$ Naval Undersea Warfare Center Division, Keyport, WA 98345, USA \\ ${ }^{6}$ Center for Advanced Life Cycle Engineering (CALCE), University of Maryland, College Park, MD 20742, USA
}

Correspondence should be addressed to Ed Habtour; ed.m.habtour.civ@mail.mil

Received 17 July 2013; Accepted 5 February 2014; Published 10 April 2014

Academic Editor: Nuno Maia

Copyright (C) 2014 Ed Habtour et al. This is an open access article distributed under the Creative Commons Attribution License, which permits unrestricted use, distribution, and reproduction in any medium, provided the original work is properly cited.

\begin{abstract}
A review of past and recent developments in multiaxial excitation of linear and nonlinear structures is presented. The objective is to review some of the basic approaches used in the analytical and experimental methods for kinematic and dynamic analysis of flexible mechanical systems, and to identify future directions in this research area. In addition, comparison between uniaxial and multiaxial excitations and their impact on a structure's life-cycles is provided. The importance of understanding failure mechanisms in complex structures has led to the development of a vast range of theoretical, numerical, and experimental techniques to address complex dynamical effects. Therefore, it is imperative to identify the failure mechanisms of structures through experimental and virtual failure assessment based on correctly identified dynamic loads. For that reason, techniques for mapping the dynamic loads to fatigue were provided. Future research areas in structural dynamics due to multiaxial excitation are identified as (i) effect of dynamic couplings, (ii) modal interaction, (iii) modal identification and experimental methods for flexible structures, and (iv) computational models for large deformation in response to multiaxial excitation.
\end{abstract}

\section{Introduction}

The study of fatigue failure was instigated in the 19th century following several catastrophic train accidents [1]. This field has evolved drastically to include substantial scientific efforts to gain an understanding of failure mechanisms in structures under dynamic loading [2-10]. The scientific studies of fatigue accelerated in the 1940s to mitigate fatigue failures seen in military systems during World War II. These studies began to include multiaxial loading in the 1960s; such studies increased significantly in the 1990s due to the proliferation of complex components in the electronics, military, aerospace and automotive platforms [2]. In spite of the significant accomplishments achieved in the twentieth century the introduction of sophisticated and high precision devices in the 2000s, such as micro/nanoelectromechanical systems
(MEMS/NEMS) and electronics, has exposed the limitation of our knowledge of fatigue due to multiaxial vibration. Researchers are still struggling to systematically model highcycle fatigue of linear and nonlinear structures under multiaxial loading; thus, prediction methods for high-cycle fatigue life remain somewhat immature. Life-cycle prediction under multiaxial dynamic loading has been shown to be extremely complex and more intractable than uniaxial models [11]. This is primarily because the validation of multiaxial models is extremely difficult since multiaxial vibration shakers, shown in Figure 1, are complex, costly, and extremely limited [12].

The initial assumption at the beginning of this literature review was that there would be an abundance of research performed in multiaxial vibration since most mechanical and electronics products are universally subject to multidegrees of freedom (MDoF) dynamic loading. However, only limited 

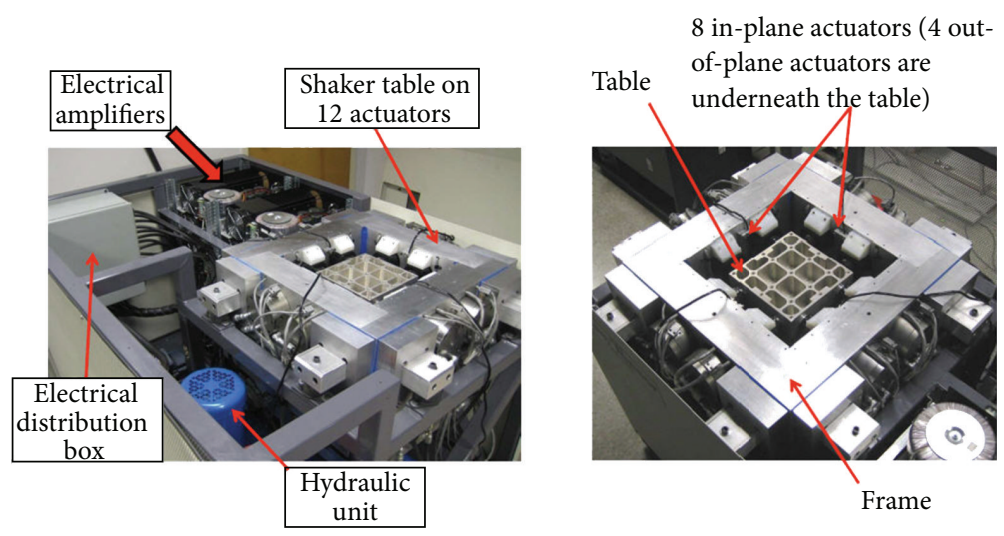

Figure 1: Six-DoF electrodynamic shaker at CALCE (with TEAM Inc. permission).

life-cycle modeling studies focusing on multiaxial vibration have been published in the literature. Analytical and experimental investigations of structures exposed to multiaxial harmonics and random loading are also scarce. Most studies found in the literature are focused on uniaxial loading. Furthermore, military and commercial standards were developed to mitigate the testing limitations by proposing sequential uniaxial excitation as a compromise and proxy for simultaneous multiaxial excitation. In qualifying products subject to vibration, it is common to test sequential uniaxial vibration profiles found in standards such as MIL-STD-810G. Unfortunately, current standards do not provide vibration profiles for simultaneous multiaxial vibration. Single axis electrodynamic and hydraulic shakers have been the prevailing tools for performing harmonic and random vibration testing. Unfortunately, uniaxial sequential testing may provide overly optimistic fatigue durability results $[10,13]$.

While several different schemes are widely used to test devices sequentially in the various axes, it is understood that they are rough approximations to the ideal of simultaneous multiaxial testing and must be in the linear regime. Uniaxial excitations are applied to test products even though most field operational data indicate that these products are exposed to multiaxial dynamic loading environments. Examples include a spacecraft launch, a military ground vehicle over rough terrains, a helicopter blade during instability, and an aircraft wing exposed to turbulent flow. Thus, serious compromises must be made in the experimental design to perform meaningful tests on a single-axis electrodynamic shaker. For example, to simulate multiaxial vibrations, the MIL-STD-810G recommends performing the vibration tests by sequentially applying single axis excitation to a test article along three orthogonal axes $(X, Y$, and $Z$ ). This can be accomplished by exciting the structure in one direction then repeating the procedure twice after rotating the structure $90^{\circ}$ each time. Depending on the complexity of the structure, this procedure may require designing a different fixture for each rotation.

Understanding the failure mechanisms due to complex vibration loading is becoming increasingly important for current systems that are progressively complex and electronically rich [14]. These failure mechanisms can be exploited through accelerated multiaxial vibration testing, which may provide reliability improvements at significantly lower cost [15]. Unfortunately, difficulties encountered in this approach have limited its application and acceptance. Some of these difficulties can be traced, in part, to a lack of understanding of the propagation of multiaxial dynamic loads from the system level to individual components. To appreciate a particular failure mechanism by means of testing, it is important to resolve the dynamic loads by simulating the actual vibration conditions, which can be accomplished with a multiaxial shaker.

The objective of this literature review is to provide engineers and researchers with an overview of the work that has been done in the area of uniaxial and multiaxial vibration. The review provides most of the significant accomplishments in the past century in uniaxial and multiaxial vibration and high-cycle fatigue. State-of-the-current technologies and state-of-the-art technologies are provided. The review is broken into four major parts: the first section focuses on the industrial studies and research in complex dynamic loading and high-cycle fatigue, whereas the second part focuses on the theoretical and experimental aspects. The third section discusses mapping fatigue to multiaxial dynamic loading. The final portion of this paper summarizes proposed and future efforts in the field of multiaxial vibration.

\section{Applied and Industrial Contribution}

This section provides an overview of uniaxial and multiaxial vibration studies performed by the automotive, aerospace, and electronics industries. These three industries have developed a great wealth of data, standards, methodologies, and models for dealing with vibration fatigue.

2.1. Automotive Applications. The automotive industry has produced an abundance of publications on the use of uniaxial and multiaxial excitation for durability and qualification testing, to meet warranty and reliability requirements demanded by consumers. A typical automobile prototype is subjected to a variety of vibration profiles that simulate operational conditions in a laboratory environment. According to Dodds and Ward [16] and Awate et al. [17] automotive manufacturers 


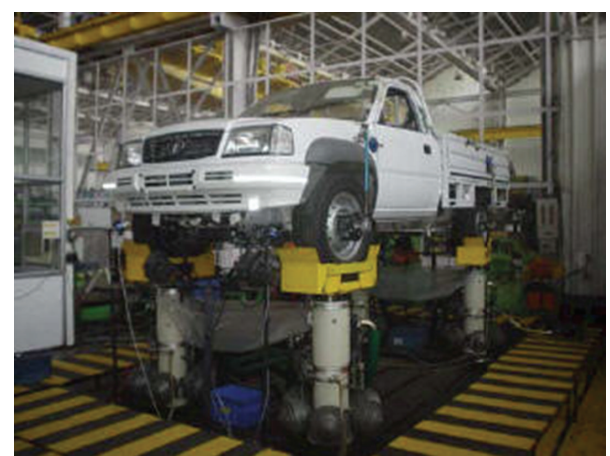

FIgURE 2: Four-post hydraulic simulator, from Awate et al. [17].

utilize accelerated life testing for critical components to meet the life-cycle requirement while reducing the testing cost. This can be accomplished by driving on various road surfaces (proving grounds) similar to those seen in the field. During testing, acceleration data are collected for the critical components. The measured conditions are then simulated on shakers in the test laboratory, where the critical components are exposed to similar dynamic conditions, but accelerated. Another approach that automotive manufacturers rely on is the four-post hydraulic shaker. This is a common testing tool for validating vehicle durability [17]. It is a relatively simple and cost effective configuration for performing a complete vehicle vibration evaluation. A typical four-post hydraulic shaker consists of four vertical servohydraulic actuators for a simple shaker to four actuators in the vertical direction and eight actuators in the transverse direction for more advanced shakers (total of twelve actuators, three actuators per post) to simulate a multiaxial environment A simple four-vertical servohydraulic shaker, which excites a vehicle through its tires, is shown in Figure 2. Similar to the component accelerated life testing, the wheels' accelerations and forces and the wheel-tobody displacements data obtained from the proving ground can be reproduced by such a shaker. The dynamic loading produced by the shaker induces stresses on the vehicle and its components. However, using a four- or twelve-hydraulic actuator shaker introduces two major limitations $[17,18]$. The first limitation is the inability to simulate the effect of rolling tires on the overall stiffness and damping of the suspension system and vehicle structure. The second issue is that hydraulic shakers have limited frequency range, in general $1-80 \mathrm{~Hz}$ [16].

Because of these limitations, estimating and modeling vibration fatigue for components in higher frequency ranges can be an arduous task. High-frequency dynamic loading, especially random loading, is a major contributor to fatigue in vehicular components [19]. These high frequencies can easily generate other high frequencies caused by rotating speeds, random vibration, and noise radiation that can potentially augment the severity of damages. These highfrequency loads are transmitted from the chassis to the vehicle body and eventually to the components [20]. One of the common multiscale hierarchical approaches for modeling fatigue in vehicular components is to model global dynamic responses of the vehicle and progressively generate the effect of these responses on the vehicle subsystems and eventually on individual components, which can be an expensive and time consuming approach. Another common approach is to rely on engineering judgment in assuming realistic boundary conditions and loads directly at the subsystem or component level. Subsequently, finite element methods (FEM) are used for stress and fatigue assessment, based on these assumptions and on linearizing approximations of the structure, which may lead to erroneous results and vehicle recalls. Liu [20] suggested a more practical approach where FEM is coupled with experimental transfer functions. Liu detailed a methodology for extracting an experimental frequency response function (FRF) that represents the body and then combining it with the FEM models.

As mentioned above, random vibration in automobiles is one of the major contributors to fatigue damage. Typically, automotive fatigue researchers rely on power spectral densities (PSDs) to represent stochastic dynamic behaviors [18, 2124]. A detailed approach to estimating fatigue life due to random vibration loading for a truck was provided by Bonte et al. [22]. They developed an analytical model where symmetric in-phase road excitations were applied to all wheels of a full truck. They also applied asymmetric excitations (180-degree phase difference) to the left and right tracks to generate outof-phase conditions. Biaxial stress power spectral densities (PSDs) were calculated from multiple random excitations and equivalent von Mises' stress PSDs were derived. Later, Bonte et al. [23] developed a new analytical approach to estimating the equivalent von Mises' stress PSDs from several random vibration inputs while accounting for phase differences. The damage ratio was then calculated based on a uniaxial fatigue analysis approach based on the Dirlik method [25]. This approach provided qualitative results for design improvements to linear structures that can be implemented as a fast tool to evaluate different design concepts and the effect of dynamic loading on fatigue life.

Unfortunately, these tests and analytical tools are not always successful in producing failures observed in the field. The Ford Corporation found that a module could pass the qualification test but fail in the field [26]. A test or health monitoring system that could capture every failure or intermittent in real time does not exist. In spite of the great wealth of fatigue research generated by the automotive industry, the industry continues to maintain the same practice of qualifying their products by subjecting them to uniaxial vibration with the option of sequential vibration testing. However, there seems to be consensus in the literature that such an approach can be both time consuming and cost ineffective and may result in the acceptance of unreliable components.

2.2. Aerospace Applications. Surprisingly, studies published in the open literature pertaining to uniaxial and multiaxial vibration testing for aerospace applications are somewhat limited. This is due to the proprietary nature of the aerospace industry. In aeronautic applications, the majority of the dynamic loads stem from turbulent flow and during landing 
and takeoff, which are multiaxial in nature. Aircraft wings, for example, are constantly exposed to multiaxial dynamic loading since the wings are connected to a flexible support, such as the fuselage. In addition to bending in the wing, the root of the wing experiences dynamic rotation because of the inherent flexibility at the point of attachment [27]. In astronautic applications, one of the most critical and persistent spacecraft design problems is the launch survivability of sensitive and expensive systems. The acceleration levels input to a typical spacecraft are over a wide frequency range from about $30 \mathrm{~Hz}$ to $2000 \mathrm{~Hz}$ or higher [15]. Billions of dollars in lost satellites or degraded performances of payloads are attributed to damage accumulated from vibration due to launch loads [28].

In spite of the lack of specificity of multiaxial vibration and fatigue in aerospace applications, most of the multiaxial loading investigations performed by aerospace researchers have focused on the dynamics of beam-like structures as idealization of the of helicopter blades, aircraft wings, or deployable solar panels in satellites [27, 29-32]. Only two major studies, at the system level, are reviewed in this section. The first study is an early investigation of the dynamics of a blade in a compressor [33]. The other is a more recent study of fatigue assessment of a military helicopter flaredispenser bracket [34]. In the study performed by Whithead [33], experimental the power spectra of vibration response were measured for blades in axial compressors exposed to turbulent flow. In deriving the equations of motion, the effect of aerodynamic coupling between the blades was assumed to be a minor effect and thus neglected. Aykan and Çelik [34] compared fatigue damage accumulated under uniaxial and multiaxial broadband random excitation. The PSD of the dynamic response was obtained for a military helicopter flare-dispenser aluminum bracket during flight. The PSD profile was used as an input for uniaxial excitation testing. However, due to lack of multiaxial excitation testing capability, the simultaneous three-axial loading was modeled using FEM to calculate the structural response. Similar to most studies found in the literature, Aykan and Çelik assumed that sequential uniaxial loadings were equivalent to multiaxial loadings. Thus, the fatigue analysis was performed in frequency domain with the assumption of linear structural behavior. They concluded that the cumulative fatigue damage in multiaxial excitations was higher than adding the damage for sequential axes even for linear structures. It is important to point out that, for military aircraft, the MIL-STD-810G provides single-axis PSD profiles for simulating the dynamic inputs in various fixed-wing aircrafts and in rotorcrafts.

2.3. Electronics Applications. One of the predominant failure modes in electronics is solder joint fatigue due to vibrations $[35,36]$. Analyses of solder joint stresses associated with uniaxial vibration are widely seen in the literature: Lau et al. [3739], Liu et al. [40], Yang et al. [41], and Zhou et al. [42]. One of the most detailed methodologies for monitoring, recording, and analyzing life-cycle vibration loads of electronics was developed by Gu et al. [43]. They developed this methodology by exciting circuit card assemblies (CCAs) in the out-of-plane direction using broadband PSD profiles. Strain data was collected for different PSD levels from a series of experiments. FEM simulation was then conducted and calibrated based on the experimental responses of the CCAs. A strain transfer function was calculated to predict the damage ratio in the solder where the structure was assumed to be linear. Unfortunately, literature does not provide any methodology that considers multiaxial vibration in electronics systems. Zhou et al. $[36,42]$ estimated vibration fatigue of $\mathrm{Sn} 3.0 \mathrm{Ag} 0.5 \mathrm{Cu}$ and $\mathrm{Sn} 37 \mathrm{~Pb}$ solders for CCAs exposed to linear harmonic uniaxial excitation. The analysis was conducted in the time domain to quantify the fatigue damage caused by harmonic excitation at the first natural frequency. In their study, they observed two competing failure sites in the solder interconnect and in the printed wiring board (PWB) copper trace just below the failed components. Several researchers studied high-cycle fatigue in CCAs exposed uniaxial harmonic and random excitations in the range of $10 \mathrm{~Hz}$ to $10 \mathrm{kHz}[36,42,44-48]$. Based on this extensive literature review, there are two multiaxial vibration fatigue studies in electronics components. The first study by Habtour et al. [15] provided a rapid analytical technique for analyzing the response of heavy/large components under biaxial random vibration excitation. A modified 2-D FEM smeared technique was used to model the CCA, which was coupled with a detailed local 3D FEM for heavy components. Based on the knowledge of the effective moment-curvature relationship near the component of interest, a local effective stiffness was calculated. This was accomplished through the use of Kirchhoff-plate moment-curvature equations. The modified smeared technique correctly predicted the overall stiffness of the CCA and produced an accurate PWB first mode frequency; however, the model does not take into account the inertial effect of the large component on the overall response of the CCA. The second study by Ernst et al. [49] is the only experimental study that exposed heavy/large electronic components to biaxial planar random excitations. This study is discussed in detail later in this paper in the section titled "Mapping Dynamic Loads to Fatigue."

\section{Theoretical Approach}

3.1. Beam Vibrations. The beam has many characteristics of typical aeronautical and astronomical structures. Indeed, high aspect ratio aircraft wings, spacecraft deployable solar panels, and helicopter rotor blades are frequently idealized as beams. Even for low aspect ratio wings, the bending and torsional deformation can be approximated by use of beam theory with an adjusted stiffness [27].

3.2. Stochastic Vibrations. There have been significant scientific contributions in stochastic vibrations since the 1950's. During that time, random vibration received significant attention due to its importance in fatigue damage in aircraft and naval ships. One of the earlier studies in random vibration of beams was performed by Eringen [50], where he derived a closed-form solution for space-time correlation functions of a simply supported beam. Eringen employed generalized harmonic vibration analysis of damped beams 
exposed to one-dimensional randomly distributed external pressure loads. His approach provided cross-correlation functions for displacements and stresses in terms of the external pressure cross-correlation function. Herbert [51] applied Markoff process and Fokker-Planck equations to investigate large vibration of a simply supported elastic beam exposed to broadband white noise external pressure acting on the entire beam surface. He obtained the joint probability density function (PDF) of the modal amplitudes using the Fokker-Planck equation. An approximate expression for the mean-squared displacement of the beam was derived and was then compared to numerical computation, which indicated a reduction in the mean-square displacement due to the nonlinearity. Herbert [51] also showed that when the deflection was sufficiently large, the first mode still represented a good estimate of the total mean-squared deflection; however, the effect of the higher modes must be considered in calculating the response of the first mode. The studies reported by Herbert lacked experimental validation. Elishakoff and Livshits [52] utilized Eringen's and Herbert's findings to produce closed-form solutions for a simply supported Euler-Bernoulli beam under random vibration with different damping mechanisms. The excitation was spatially and temporally random stationary white noise induced on the entire bottom surface of the beam. Elishakoff stated that using a span averages approach instead of the maximum random vibration responses could yield an underestimate of the stresses. In a different study, Elishakoff [3] generalized the Eringen problem to include the effect of axial loading on a beam exposed to a random transverse load. Later, Elishakoff et al. [53] employed a stochastic linearization to investigate large amplitude random vibrations of simply supported and clamped beams on an elastic foundation under a stochastic loading. He stated that, for different boundary conditions and the loading patterns, the stochastic linearization method was superior to the classical stochastic technique, especially in nonlinear structures. Ibrahim and Somnay [54] investigated the response of an elastic Euler-Bernoulli beam with one frictional support at each end, which was exposed to single point harmonic and stochastic excitations (randomized only in time). The beam was allowed to slide on the two frictional supports. A Monte Carlo simulation was utilized to estimate the beam mean-square response for the stochastic excitation case. For the harmonic excitation case, the quality factor improved as the excitation frequency increased beyond the resonance frequency. The friction in the random excitation case caused a significant reduction of the system mean-square response.

3.3. Nonlinear Vibrations. Substantial attention has been devoted to nonlinear dynamics and vibrations of beams because of their vital importance in many engineering applications and fatigue problems. One of the most cited studies in nonlinear dynamics is the work of Hodges and Dowell [32], where they developed the multiaxial equations of motion for a rotor blade, idealized as a cantilevered beam, using Hamilton's principle. They maintained the cubic nonlinear terms and included the effect of warping. Ho et al. $[55,56]$ examined free and forced nonplanar oscillations of fixedfixed and cantilever inextensional beams, respectively. Ho et al. reduced the nonlinear partial-differential equations of motion to two coupled nonlinear ordinary-differential equations using separation of variables, where they assumed only one mode in each plane. They also ignored the axial inertial and Poisson effects. It was concluded that whirling oscillations might occur for significantly large excitation amplitude. Crespo da Silva and Glynn [57, 58] developed a set of partial-differential equations for flexural-flexuraltorsional motions of inextensional beams, which contained geometric and inertial nonlinearities. It was found that the geometric nonlinearities were critical for low modes and must not be neglected. Later, Da Silva [29] extended the above approach to extensional beams where he constructed partialdifferential equations for flexural-flexural-torsional motions. The axial displacement due to warping was considered in the derivations. These equations were then applied to study the nonlinear response of an extensional cantilever beam to a fundamental resonant excitation [59]. Crespo da Silva concluded that the nonlinear terms due to midplane stretching were predominant in extensional beams. Nayfeh and Pai [60] and Pai and Nayfeh [61] also investigated nonlinear nonplanar responses of inextensional cantilever beams to parametric and resonant excitations using the partial-differential equations of motion developed by Crespo da Silva and Glynn [58]. The method of multiple scales was utilized to construct nonlinear first-order ordinarydifferential equations governing the modulation of the amplitudes and phases of the interacting modes in each plane. They conclude that the geometric nonlinear terms had a stiffening effect, whereas the inertial terms had a softening effect. Crespo da Silva and Zaretzky [30] and Zaretzky and Crespo da Silva [62] continued to study the nonlinear response of an inextensional beam exposed to one of the flexural modes resonant excitation. The method of multiple scales was applied to the governing partial-differential equations to produce the equations of motion that provide the capability for modulating the amplitudes and phases of the beam interacting modes. Arafat et al. [63] showed that the partialdifferential equations of motion of Crespo da Silva and Glynn $[57,58]$ can be derived using Hamilton's extended principle. Nayfeh and Arafat used the method of multiple scales to the Lagrangian terms to derive the modulation equations for amplitudes and phases of the two interacting modes [64]. Nayfeh and Arafat [65] and Arafat [66] derived the Lagrangian equations of motion for nonlinear flexuralflexural-tensional vibrations of symmetric laminate composite and isotropic metallic long slender cantilever beams with nearly square cross-sections under uniaxial harmonic excitation of the base. Perturbation procedure was then applied to establish approximate solutions for the weakly nonlinear equations of motion. The beam was assumed to be inextensible with negligible torsional inertia, leading to two partial-differential equations governing the motions of the beam. Banerjee [67] provided a methodology for deriving exact expressions for the mode shapes of free vibration of composite beams. The effect of material coupling between the bending and torsional modes was considered. The equations 
of motion of the bending-torsion were solved analytically for bending and torsion. Malatkar and Nayfeh $[68,69]$ and Malatkar [70] extended Arafat's equations of motion development to their experimental and theoretical study of the response of a flexible long cantilever beam exposed to external single axis harmonic plane excitation near the beam third mode. They observed that the beam response contained significant contributions from the first mode when the beam third mode amplitude and phase were slowly modulated. The energy leakage between these modes depended on how close the modulation frequency was to the frequency of the first mode.

Anderson et al. [71] experimentally investigated the response of a thin steel cantilever beam with an initial curvature to a combination parametric excitation exposed to uniaxial base excitation. The first four natural frequencies were $0.65,5.65,16.19$, and $31.91 \mathrm{~Hz}$. Their study suggested that over a range of forcing frequency above $32 \mathrm{~Hz}$, the first and fourth modes were initiated by a combination parametric resonance with the first mode dominating the response. The experimental results confirm the occurrence of external subcombination resonances in structures found in the study by Dugundji and Mukhopadhyay [72]. These resonances can be utilized as mechanisms for instigating large amplitude lowfrequency modes with high-frequency excitations.

The dynamics of nonlinear beams with complicated boundary conditions were also investigated. Dowell [31] performed an analytical study of large motion of axially sliding beams with dry friction damping. In Dowell's study, an EulerBernoulli beam pinned at both ends was considered; however, the beam was fixed at one end against the axial motion and with a sliding restraint. Coulomb dry friction damping was assumed. The Galerkin modal solution method was applied for a single mode. Dowell concluded that, for large beam response, damping was created due to dry friction and equivalent to a linear viscous damper. Tang and Dowell [73] performed a numerical and experimental study to support Dowell's analytical work [31] using a pinned-pinned beam under single axial harmonic excitation for slip and no-slip conditions. Their model was more reliable for the first mode than higher modes and can be applied to a beam with wellseparated modes.

Sophistications were added to beam models to idealize more complex structures such as antenna and radar structures and aircraft wings. This can be achieved with cantilever beams or L-shape beams models with tip mass under a base excitation. To [74] analyzed the dynamics of an antenna by deriving the natural frequencies and mode shapes of a cantilever beam with an eccentric tip mass under a base excitation. To assumed small deflection and neglected the effect of the axial deflection due to the heavy mass at the tip. The model was appropriate only for linear structures with uniaxial excitation. Later, Cartmell and Roberts [75] conducted a theoretical and experimental investigation of the stability of a cantilever beam with tip mass having two simultaneous combination parametric bending and torsion resonances. The multiple scales method was utilized. It was possible to reach an agreement between theoretical and experimental results within limited ranges of excitation

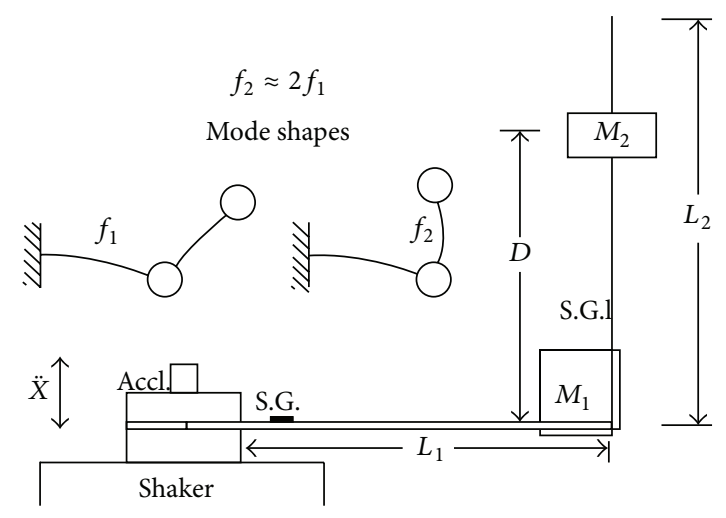

FIgURE 3: L-shape structure excitation, Balachandran and Nayfeh [77].

frequency, but unattainable in periodic modulation regions. Cartmell and Roberts did not consider the effect of inherent nonlinearities in the system. In 1990, Balachandran and Nayfeh [76] reported the planar response of a flexible Lshaped beam-mass structure with the second natural frequency twice the first natural frequency of the structure, as shown in Figure 3. They showed that weakly nonlinear analysis can be used to qualitatively and quantitatively predict the response of an internally resonant structural system subjected to small primary resonant excitations. Balachandran and Nayfeh developed the Lagrangian for weakly nonlinear motions of the L-shape structure where they assumed that the structure was undamped. It was possible through their approach to identify the Hopf bifurcations, thereby ascertaining the parameters that control the possibility of periodic and chaotic modulated motions. Later, Balachandran and Nayfeh [77] presented experimental results on the influence of modal interactions on the nonlinear response of the Lshape structure. The major conclusion was that the frequency relationships between the different modes of oscillation in the structures led to modal interactions during the resonant excitations and nonlinear responses. Jaworski and Dowell [78] performed a theoretical and experimental investigation of the free vibration of a cantilevered beam with multiple cross-section steps. The natural frequencies were obtained experimentally using modal impact testing. The experimental results were then compared against Euler-Bernoulli beam theory solutions from Rayleigh-Ritz FEM results, where the asymptotic approximation was utilized for higher modes to avoid numerical error. A detectable difference in the first in-plane bending natural frequency was noted between the beam theory results and those of the higher-dimensional FEM models and experimental observation.

3.4. Microsystems Vibrations. For the past two decades, consumers' demand for miniaturized smart devices has continued to increase at a considerable pace. As a result, microsystems devices have become ubiquitous in almost every product that humans interact with on daily bases such as smart phones, computers, medical devices, and automobiles. Recent advancements in microsystems fabrication have 
allowed for new possibilities in designing an assortment of microstructures such as piezoelectric energy harvesters, sensors, accelerometers, bistable piezoelectric devices, microgyroscopes, and MEMS $[79,80]$. Fortunately, these microstructural components' behavior can be formulated based on the Euler-Bernoulli beam or Timoshenko beam theory [8185]. Researchers have investigated both linear and nonlinear vibration based energy harvesting devices, in which these devices were modeled using beam theory [84, 86-90]. Beam theory was also extended to nanomechanical cantilevers, such as the efforts performed by Villanueva et al. [91]. Some of these microstructures are submerged in fluids with various viscosities to achieve optimal performance, such as the work presented by Green and Sader [86]. They developed a theoretical model for the torsional response of a linear cantilevered beam excited by an arbitrary driving force while submerged in a viscous fluid. Esmaeili et al. [84] developed equations of motions for a microgyroscope, which was modeled as a linear cantilever beam with a tip mass exposed to excitation at the base. Their governing equations were derived from Hamilton's principle with a 6-DoF base motion where the torsion was neglected. Esmaeili et al. resolved the measurement error in oscillating gyroscopes due to cross-axis effects resulting from a combination of lateral rotation and longitudinal speeds in the linear regime.

Ansari et al. [79] developed an exact frequency analysis of a rotating beam with an attached tip mass while the beam undergoes coupled torsional-bending vibrations, where the base angular velocity was the instigator of the coupling. The extended Hamilton principle was utilized to derive the coupled equations of motion and the associated boundary condition. Ansari et al. demonstrated that the undamped structure experiencing base rotation has complex eigenvalues, which revealed a damping behavior. They also showed analytically that increases in the rotational velocity cause an increase in the frequencies. Later, Ansari et al. [81] presented a more complex vibration and parametric sensitivity analysis of a vibrating gyroscopic microdevice. The device consists of four beams attached to a stiff substrate with a mass at the center, as shown in Figure 4. Thus, the device experienced coupled flexural and torsional responses. The results obtained from their analysis revealed that an increase in the base rotation increased the real and imaginary components of the eigenvalues.

Kumar et al. [92] studied the effects of structural and inertial nonlinearities on near resonant response for a flexible cantilever inextensional beam exposed to base excitation combined with simultaneous parametric excitation. They conducted base excitation experiments for a cantilevered spring steel beam: $190 \times 19 \times 0.5 \mathrm{~mm}^{3}$, which was oriented at $80^{\circ}$ angle to induce both direct and parametric excitations. The energy method was utilized to derive the governing equations for their structure, where the rotational inertia and the torsion were assumed negligible [93]. Kumar et al. claimed that this work provided a baseline understanding of the effect of nonlinearities on parametrically excited systems.

It was apparent during this literature review that resonant energy harvesters were analyzed and designed for uniaxial base excitation at a single frequency, whereas many

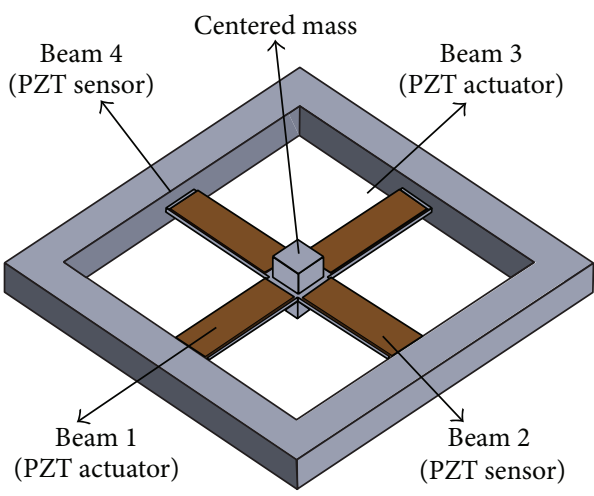

FIGURE 4: Schematic of a rocking-mass gyroscope Ansari et al. [79].

real-world applications encompass multiaxial excitations, broadband spectrum, and time varying dynamic loading. In terms of multiaxial excitations for microsystems, the only study that can be found in the open literature is the work of Esmaeili et al. [84]. Limited studies were found in the literature that investigated energy harvesters for time varying broadband random excitations [80, 85, 94]. Ali et al. [94] employed a linearized stochastic methodology to a cantilever beam configuration energy harvester exposed to uniaxial stationary Gaussian broadband base excitations. Wickenheiser [80] developed an optimization methodology for designing linear and nonlinear vibration energy harvesters for maximizing power production by vibrations due to uniaxial broadband random loading environments at low frequencies. Wickenheiser [80] also linearized his approach by employing a close form approximation. Stanton et al. [85] investigated the nonlinear dynamics and stability of a broadband energy harvester under broadband random excitation. The harvester was modeled analytically and numerically as a cantilever beam with tip mass under uniaxial broadband base excitation, which were validated experimentally. Stanton et al. [85] considered the bifurcation parameter within the harvester as either a fixed or an adaptable tuning mechanism for enhanced sensitivity to broadband random excitation. Later, Stanton et al. [87] modeled nonlinear damping of uniaxial weakly excited piezoelectric actuators, which included nonconservative piezoelectric constitutive relations. In their analysis, a piezoelectric actuator was idealized as a cantilever beam with tip mass. Stanton et al. showed that the tip mass precipitated nonlinear resonances at lower base excitations. Stanton et al. [88] extended the method of harmonic balance to estimate the presence and impact of a bistable piezoelectric inertial generator. In their model, they included nonlinear dissipation and cubic softening influences in the electroelastic laminates. Westra et al. [89] investigated the interactions between a directly and a parametrically excited mode of a clampedclamped micromechanical beam resonator. They were able to detect the motion of a parametrically excited mode that provoked a change in another mode of the same structure. They demonstrated that the parametric excitation of one mode instigated a change in the fundamental frequency of the other modes. 
3.5. Nanosystems Vibration. Nanomechanical cantilevers recently received increased consideration in biomedical sensing and prognostics and diagnostics applications. The biomolecular community deserves the majority of the credit for accelerating the research in nanomechanical cantilevers by generating applications that ranged from high-throughput biomolecular detection to bioactuation [95]. Biomolecular researchers and physicists suggested that the cantilever motion of DNA can be manipulated by controlling the entropy change during DNA hybridization [95]. Later scientists were able to measure the resonant frequency shift based on a nanomechanical cantilever augmented with an actuating layer for the detection of a prostate-specific antigen in fluid setting [96]. Dorignac et al. [97] estimated the stochastic dynamic response of biofunctionalized structures by utilizing the nanomechanical cantilever beam idealization. Their model assumed that the structure was linear and immersed in viscous fluid, where random excitations are generated by biomolecular interactions only; the model ignored any inertial loading. Salehi-Khojin et al. [98] presented a modeling approach to dynamic characterization of nanomechanical cantilevers with geometrical discontinuities. The linear analysis provided eigenvectors and eigenvalues for the first three modes and compared them with those obtained from the experiment and theory for uniform beams. The uniform beam theory was unsuccessful in predicting the system's response, while the discontinuous beam model provided better estimates. Seena et al. [99] studied the mechanical and dynamic characteristics of highly sensitive piezoresistive nanomechanical cantilever sensors in detecting explosives in vapor phase, where the system was assumed to be linear. There were limited studies that investigated the nonlinear dynamic characterization of nanomechanical cantilever beams. Villanueva et al. [91] investigated the fidelity of Euler-Bernoulli's beam theory in estimating the dynamic response of nanomechanical cantilever beams in the nonlinear domain, where the beam was exposed to single axial harmonic base excitations. They showed that the Euler-Bernoulli's beam theory predictions differ significantly from their measurements for the nonlinearity of the first fundamental mode.

\section{High-Cycle Fatigue}

The main objective of this section is to provide a general overview of the available literature on high-cycle fatigue, with an emphasis on uniaxial and multiaxial harmonic and random dynamic loading. A brief review of early fatigue studies is provided; however, the core of this review is focused on recent theoretical, experimental, and computational advancements. The railway industry deserves the credit for instigating serious scientific studies for understanding, analyzing, classifying, and mitigating cyclic fatigue in the late 1800 's. One of these early studies was by Wohler, who is considered one of the earliest pioneers of fatigue, for investigating fatigue failures in railway carriage axles [2]. Industrial investment in fatigue studies in the early 20th century led to the popular exponential relationships between stress amplitude and loading cycles by Dowling and the secondary effect on life due to mean stresses by Suresh [2, 100]. In many of these efforts, the focus was on stresses due to a constant amplitude sinusoidal loading, which led to the sinusoidal fatigue equations found in many fatigue textbooks $[2,101]$. Significant considerations were dedicated to examining the mean stress effects for fatigue in welds due to harmonic and random loading $[102,103]$.

4.1. Uniaxial Loading. There are many circumstances in fatigue problems where it is unrealistic to always consider a constant amplitude sinusoidal loading. Examples of such cases are components in an off-road vehicle, electronic components in a rotorcraft, and an aircraft wing exposed to turbulent flow. Methods and standards were developed to determine the time to failure (TTF) with constant and variable loading amplitudes. The most well known is the "linear cumulative damage rule" for variable amplitude loading, which was attributed to Palmgren [104] and later popularized by Miner [105]. The Palmgren-Miner rule reasoned that fatigue damage is cumulative; thus, each stress cycle contributed to damage as a function of the number of cycles to failure for that cycle amplitude. Their linear cumulative damage approach neglected any sequence effects that may change fatigue life, that is, low amplitude stress followed by high amplitude versus the opposite sequence. Later, Miles [106] utilized the Palmgren-Miner cumulative damage rule for analyzing narrowband random vibration fatigue. The linear summation of damage was extended to an integral of stress peaks scaled by the PDF of the peaks for a narrowband random vibration fatigue problem. The resulting damage equation was a function of the sinusoidal stress versus the number of fatigue cycles (known as S$\mathrm{N}$ curve), the material fatigue constants, and the standard deviation of stress. Crandall [107] and Lin [108] produced influential studies on nonlinear response PDFs and their effect on fatigue. Crandall developed equations for the rates of zero crossings for nonlinear non-Gaussian systems for structures with nonlinear restoring forces. The analytical relationship that Lin developed for nonlinear stress PDFs was based on a quadratic displacement to stress equation, where the displacement PDF was assumed to be nonlinear.

The narrowband random vibration loading case, deservingly, received significant attention in the 1960's. Bendat [109] proposed the first significant step towards a method of determining fatigue life from the PSDs. For a narrowband time history loading, Bendat assumed that corresponding depressions of comparable size would follow positive peaks in the time history. Using this method, it was shown that the PDF of peaks for a narrowband signal tended towards a Rayleigh distribution. Bendat used a series of equations derived by Rice [110] to estimate the expected number of peaks using moments of area under the PSD. The narrowband solution was extremely conservative when broadband time history profiles were used. This was due to the assumption that peaks were matched with corresponding troughs of similar magnitude. The narrowband random vibration loading case was extended to arbitrary stress cycles using loading 
cycle versus amplitude counting methods. The narrowband time-domain approach emerged as the standard method in estimating the fatigue life of structures, widely known as the "rainflow" cycle counting method and attributed to Matsuishi and Endo [2].

To overcome the conservatism in the narrowband method of Bendat, Dirlik [25] proposed an important and extensive fatigue model that corrected for Bendat's method. Dirlik's model was based on a closed-form expression for the PDF of rainflow ranges using a Monte Carlo technique. For a given set of material properties, life estimates may be made for any number of different component geometries of load histories. Bishop [111] and Bishop and Sherratt [112] enhanced the rainflow cycle counting method by adding more mathematical rigor to improve its robustness and accuracy. The time-domain based theoretical approach formulated by Bishop was computationally intensive and showed little improvement on the accuracy over Dirlik's empirical model. Currently, the Dirlik's approach is widely applied to fatigue problems and fatigue codes such as HBM nCode and MSC-NASTRAN $[21-23,113]$.

Stochastic FEM provided high accuracy for antisymmetric laminates with different boundary conditions under transverse random loading. Sweitzer [9] developed statistical methods for determining TTF for nonlinear clamped steel beam subjected to random loading. Broadband uniaxial base acceleration was applied with a frequency range from 20 to $500 \mathrm{~Hz}$ for $0.5,1,2,4$, and $8 \mathrm{G}_{\mathrm{rms}}$. The total strain was predicted by summing the strains from the linear, square, and cubic displacements. Sweitzer observed that the displacement PDF became skewed, that is, kurtosis less than 3.0, while the acceleration PDF was skewed in an opposite direction, but the velocity remained Gaussian. Sweitzer was unable to explain kurtosis behavior of the displacement, velocity, and acceleration as the system became more nonlinear.

Most recent work in high-cycle fatigue with application to random loads was the development of an analytic model by Paulus et al. [11] to predict the remaining life of a cantilever beam with notches experiencing random vibration excitation. The model utilized Paris' law to estimate fatigue life, where only the input power spectral density and damping factor were required. The model applied linear elastic fracture mechanics for crack propagation and included the shift in frequency that resulted from the crack growth. Habtour et al. [114] developed an FEM model to predict the stress intensity and natural frequency during damage accumulation. The analytical model developed by Paulus et al. was coupled with the FEM to predict TTF for complex geometries for which stress intensity values were not available.

4.2. Multiaxial Loading. The autoregressive moving average (ARMA) model was applied in fatigue problems by scientists. Leser et al. [4] discussed the use of ARMA for stationary variations and Fourier series model for nonstationary variations. They obtained strain history of an automotive front suspension component driven through proving ground maneuvers. Critical fatigue damage plane was selected, followed by rainflow cycle counting of the strain data. The critical plane approach involves obtaining the maximum shear strain and the plane that acts on it, then using the maximum normal stress acting on the plane to calculate an effective stress [2]. A multiaxial fatigue model, valid for proportional loading, was employed, and two fatigue failure modes due to normal strain and shear strain were considered. Reconstructions using the ARMA model introduced a number of large cycles that are not present in the original loading; all reconstructions were tending to be biased toward shorter lives. Lu [115] applied the ARMA model to higher-order nonlinear beams and composite plates subjected to stochastic loading. A fourth-order nonlinear beam equation was examined to study the effect of rotary inertia and shear deformation on the root mean square (RMS) values of displacement response. A linearly coupled equivalent linearization method was applied to the simulated data of nonlinear beams. Reasonable estimations of both the nonlinear frequencies and the power spectral densities were shown. However, Lu stated that accurate results for MDoF systems and other linearization techniques need to be explored for the higher-order beams.

The usability of the energy parameter, being the sum of the elastic and plastic strain energies in the critical plane, for structures experiencing cyclical loading received significant attention from fatigue experts. Lagoda et al. [116] experimentally evaluated its use by exposing steel specimens to biaxial nonproportional random tension and compression loads. They developed an algorithm to predict fatigue life under a biaxial stress state in high-cycle regimes using the energy parameter. Lagoda et al. concluded that normal strain energy density in the critical plane seemed to be an efficient parameter for fatigue life prediction under random and cyclic nonproportional loading conditions in high-cycle fatigue. Pitoiset et al. [6] studied multiaxial fatigue of structures exposed to random vibration. They developed frequencydomain methods for estimating the high-cycle fatigue life of metallic structures [117]. The cycle counting concept was extended to multiaxial random processes. The multiaxial rainflow method consisted of counting rainflow cycles on all possible linear combinations of the random vector components. Pitoiset and Preumont frequency domain methods were computationally more efficient than the time-domain approach and with reasonable correlation with the timedomain method in terms of localizing the critical areas in the structure. They also proposed the frequency domain implementation of Crossland's failure criterion, which also was found in very good agreement and much faster than its time-domain counterpart. Pitoiset et al. [118] showed that a mean value other than zero determined the presence of a very low frequency component that did not exist in the real process. This incoherence was mitigated by the construction of a process having the same RMS of von Mises stress, but with correct frequency content. This approach did not take into account phase differences between the multiaxial stress components. Carpinteri et al. $[119,120]$ investigated theoretical and experimental application of the weight function method to estimate the principal stress directions under multiaxial random loading. The stress tensor and its eigenvectors (principle direction cosines) changed at each time increment. The Euler angles were calculated from the 
matrix of the eigenvectors for a generic time instant and then the angles were averaged by employing suitable weight functions. The experimental data were successfully correlated with the theoretical model using the maximum principal stress direction estimated by the weight function method. Liu and Mahadevan [5] developed a model where a multiaxial high-cycle fatigue principle based on the critical plane was correlated with the fatigue crack plane. They introduced an adjustment factor to consider the effect of the mean stress, which can be calibrated by utilizing experimental fatigue results. Liu and Mahadevan [121] extended the model to predict the fatigue life of a composite beam under off-axis loading, which caused proportional multiaxial stress within the material. Later, Liu [122] extended the same model for composite beams under uniaxial and biaxial fatigue loading at a frequency of $10 \mathrm{~Hz}$. The results of the proposed fatigue model were validated experimentally for low frequency loading.

In high-cycle fatigue, probabilistic methodology is common in assessing the reliability of structures subject to multiaxial random loading. Lambert et al. [123] developed a probabilistic approach for structures exposed to Gaussian random loading with a nonzero mean. This approach was used to estimate the octahedral shear stress distribution for stationary random stresses. A Monte Carlo simulation was then employed to characterize the octahedral shear stress distribution. According to the authors, the experimental results were not available; thus, errors may have occurred due to the quality of the random process generator and the limited frequency range of the PSD input load, which was approximately 5-100 Hz. Braccesi et al. [124] reduced multiaxial stress analysis to an equivalent uniaxial process that defined random process in the time and frequency domains. This analytical approach was based on the energy contents of the shear stress acting on the planes belonging to the octahedral cone [125]. Allegri and Zhang [126] applied the inverse power laws to assess the fatigue damage of structures exposed to accelerated broadband Gaussian random vibration. A scaling law was used to relate the test time in a laboratory to the actual operational life. Allegri and Zhang stated that fatigue accumulation in a random multiaxial loading environment was more rapid than for constant amplitude loading; that is, the S-N curve slope was larger in the case of random loading. This implied that the correct value of the exponent, which appears in the inverse power scaling law, was estimated by random fatigue tests on representative material samples. Zhou et al. have also pointed the same observations for uniaxial random vibration [42].

One of the most common approaches found in the literature was the application of stochastic analysis that combined structural failure models with linear FEM to develop a methodology for the reliability assessment [127, 128]. Segalman et al. [7] provided an approach for calculating the RMS von Mises stresses for structures loaded randomly. Segalman et al. estimated the RMS von Mises stresses from stress component transfer functions that were extracted from the FEM. The RMS stresses were calculated directly from the linear stress and displacement modes and compared to the traditional Miles' approach, which uses a spectrum of root mean square acceleration response to a random PSD applied to a single degree-of-freedom system [101]. Lei and Qiu [127] developed dynamic stochastic FEM to study the dynamic response of frame structures with stochastic parameters to dynamic excitation. The dynamic response of random structure was analyzed using a perturbation approach and modal superposition. They provided linear numerical examples to indicate that using dynamic stochastic FEM reduced the computation time while improving accuracy of the solution for the dynamic analysis of structures with stochastic parameters of dynamic excitation. However, the randomization was applied to the structural parameters, that is, mass and stiffness, but not for the excitation. Similarly, Lagoda et al. [129] developed an algorithm for estimation of fatigue life under multiaxial random vibration using spectral methods based on fatigue experiments performed on steel samples. The method retained the accuracy of the linear FEM model and modal analysis. Tibbits [130] extended the approached developed by Segalman et al. to calculate the percentiles of von Mises stress in linear structures subjected to random loads having nonzero mean values. He constructed von Mises stress statistics as a series of noncentral Chi-square distributions. The desired precision of the model was based on the number of terms in the series. Guechichi et al. [131] proposed a method for predicting the fatigue life for different materials subjected to constant amplitude multiaxial proportional loading that covered highcyclic fatigue. FEM was developed to evaluate the fatigue life and to localize the critical region. Two cases were solved: the first case was a rectangular plate with low thickness under single axial and alternating bending loads; the second case was a circular cross-section rod subjected to uniaxial load and alternating torsion moment. The Crossland criterion and FEM analysis were used to compute the maximum equivalent stress. McNeill [128] provided statistical failure prediction of orthotropic composite plates under random loading. Stochastic FEM solutions of damaging load of the structures were obtained with layerwise plate theory. Firstorder perturbation technique was utilized to estimate the mean and variance of failure.

\section{Experimental MDoF Vibration Studies}

The typical product development approach is an iterative cycle known as design-prototype-test-fix [45]. Unfortunately, this process is time consuming and requires expensive physical prototyping and testing. The lack of reliability prediction capability of a product leads to deficiency in its development. To overcome this impediment, the design-prototypetest-fix approach was greatly modified in the electronics industries, with the introduction of high accelerated life testing (HALT) methodology during the prototyping and qualification stages. This can be accomplished by utilizing a HALT shaker table/chamber, shown in Figure 5. A typical HALT chamber has a broad frequency spectrum between 10 and $10 \mathrm{kHz}$ and runs from 1 to $150 \mathrm{G}_{\mathrm{rms}}$. The intent of HALT is to accelerate the failures in electronic devices by applying a higher than normal stress to failure while assessing the design 


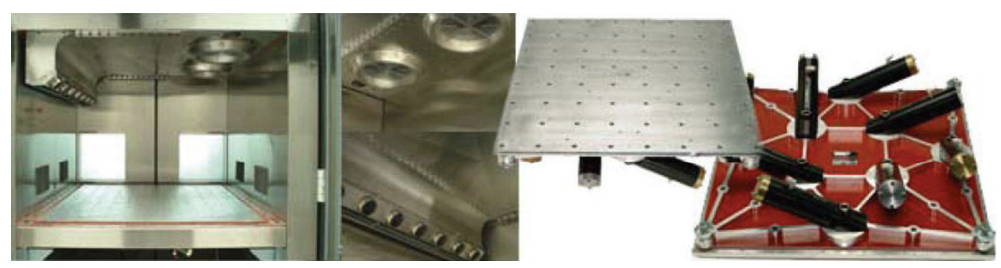

FIgURE 5: High accelerated life testing (HALT) chamber [15].

robustness through rigorous root cause failure analyses. The basic idea of HALT is to produce repetitive shocks to the shaker table using multiple pneumatic actuators at different locations of the table, thus producing multiaxial energy. Thus, the device under test is exposed to uncontrolled broadband multiaxial random excitation, with the exception of the RMS acceleration value. Furthermore, the HALT chambers are capable of exposing the test article to thermal stresses, and in some cases to humidity while it is under vibration. Designers and quality engineers have utilized HALT testing to expose design weaknesses that would eventually emerge as field failures [14].

Unfortunately, HALT provides only a qualitative rather than a quantitative understanding of the failure modes and mechanisms due to two limitations [14]. First, the only acceleration input to the actuators that can be controlled is an acceleration RMS, $\mathrm{G}_{\mathrm{rms}}$; thus, the only excitation that can be achieved is a quasirandom vibration. The second limitation is the fact that HALT uses pneumatic actuators; consequently, it is impossible to control the energy input to each axis individually. Due to these limitations, it is nearly impossible to ascertain the most dominant failure mode or the axial load that initiates the damage. It is also impossible to precisely correlate structural failure during HALT to life-cycle seen in the field.

Due to the limitations of single axis electrodynamic shakers, hydraulic actuators, and HALT shakers, researchers are currently investigating the utility of multiaxial electrodynamic shakers to understand the response of structures exposed to multiaxial vibrations and subsequently the failures due to these complex dynamics. However, studies evaluating the merits of multiaxial vibration testing using multiaxial electrodynamic shakers are very limited. This deficit is attributed to high cost constraints associated with these shakers. Only a few investigators such as Whiteman and Burman [10, 13], French et al. [12], Gregory et al. [132], and Ernst et al. [49] have pointed out the shortcomings of the sequential single axis vibration method. They have also reported evidence of differences in failure modes and fatigue life for multiaxial loadings versus single-axis inputs by utilizing multiaxial electrodynamic shakers. These studies are discussed in detail below.

Some of the limited work performed using multiaxial shakers was by Füllekrug [133], who characterized the modal response in the frequency and time domains of a structure under base excitation using a hydraulic shaker that had limited frequency range from 0 to $120 \mathrm{~Hz}$. Füllekrug developed kinematic relationships between loads at the base

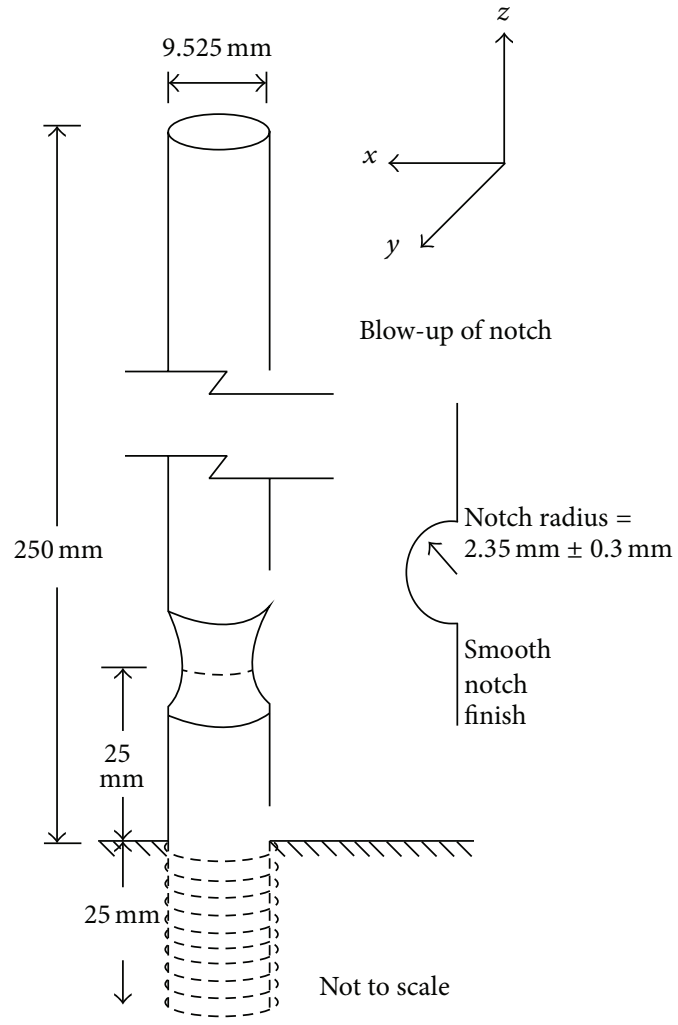

Figure 6: Dimensions of samples tested by Whiteman and Burman [10].

and structural responses due to these loads. The primary conclusion was that the frequency domain was best suited for a general and reliable modal identification of linear systems, whereas the time-domain method was more suited for analyzing transient vibration. Whiteman and Burman [13] investigated the differences between fatigue mechanisms and the effects of uniaxial versus triaxial testing. The samples used in this study were $250 \mathrm{~mm}$ long aluminum beams with a $9.5 \mathrm{~mm}$ diameter and a $0.235 \mathrm{~cm}$ radius notch stress concentrator around the entire circumference of each specimen as shown in Figure 6. Whiteman and Burman [10] performed a uniaxial random excitation experiment in the transverse direction and then repeated the same test for sequential excitation in the axial direction followed by the transverse direction. The random vibration acceleration inputs were 3.0, 3.5, 4.0, and $4.5 \mathrm{G}_{\mathrm{rms}}$ with a frequency range from 15 to $85 \mathrm{~Hz}$. The tests were then repeated using simultaneous 

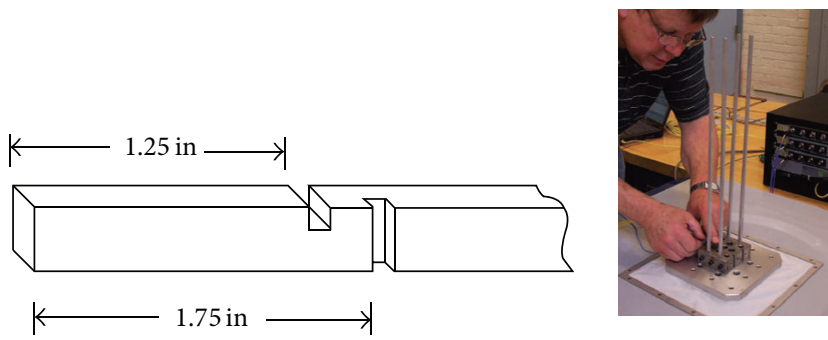

FIGURE 7: Dimensions of samples tested by French et al. and test setup [12].

triaxial excitation. It was found that the excitation in the axial direction did not weaken the specimens; on the contrary, it increased the samples' fatigue life. Whiteman and Burman [10] believed that work or strain hardening took place during the axial excitation portion of the second set of tests, which increased the fatigue failure resistance in the transverse direction. In the triaxial vibration experiments, the stresses that eventually caused fatigue failure were predominantly in the axial direction. However, simultaneous triaxial excitation accelerated the crack initiation more rapidly. By comparison, the TTF for the single axis experiments was appreciably longer than the triaxial experiments for the same input energy level.

French et al. [12] performed durability experiments on notched beam specimens using both sequential uniaxial and simultaneous biaxial testing on a TEAM tensor triaxial shaker, which was electrodynamically driven. The specimens were $19 \times 0.25 \times 0.25$ in $^{3}$ aluminum beams with notches located at two adjoining sides of the beam, as shown in Figure 7. One notch was normal to a transverse excitation ( $x$-direction) while the other notch was normal to the other transverse excitation ( $y$-direction). The notches were introduced to act as stress concentrators with depth of 0.08 in. The notch normal to $y$-direction was 0.5 in above the notch normal to the $x$-direction, as shown in Figure 7. The base excitation signal was a sine chirp from 10 to $35 \mathrm{~Hz}$ over $30 \mathrm{~s}$. The peak-to-peak acceleration amplitude was held constant at $4 \mathrm{G}$. The sequential uniaxial and simultaneous biaxial experiments produced different TTF, different failure distributions, and different failure modes. French et al. concluded that sequential uniaxial testing generally takes longer time to conduct than simultaneous multiaxial testing. Furthermore, the results from the sequential uniaxial testing are prone to produce questionable results. Unfortunately, the bandwidth in this study was limited and inapplicable to realistic structures.

At Sandia National Laboratories, Gregory et al. [132] investigated the prospect of using a six-DoF multiaxial electrodynamic shaker, developed by TEAM Inc., to illustrate the importance of multiaxial excitations in performing realistic tests. Dynamic characterization experiments were performed in uniaxial and multiaxial modes to compare the responses of a structure under the different loadings with bandwidth of $10-2000 \mathrm{~Hz}$. The specimen used for this experiment was a short rectangular aluminum beam with a lumped mass mounted at the tip, as shown in Figure 8. Acceleration PSD

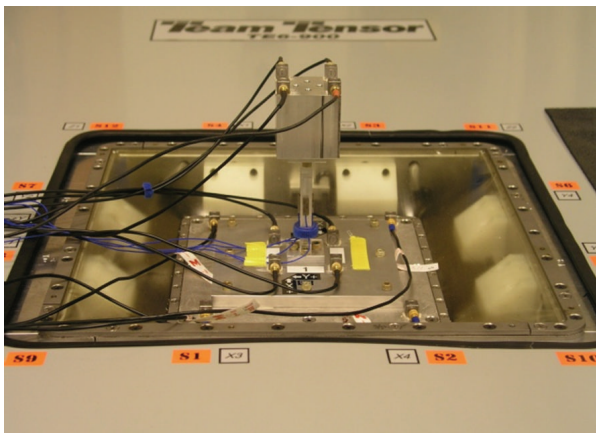

FIGURE 8: Simple structure under multiaxial loads [132].

input level of $0.0032 \mathrm{G}^{2} / \mathrm{Hz}$ was chosen to yield an overall level of $2.5 \mathrm{G}_{\mathrm{rms}}$ for the $X, Y$, and $Z$ translations. A spectral FEM model of the structure was constructed to investigate the differences in the calculated von Mises stresses. According to Gregory et al., the control system was configured for a full six-DoF random vibration input from 20 to $2000 \mathrm{~Hz}$ with zero coherence between the inputs. The experiment was then configured for uniaxial translation for each DoF. The PSD levels were selected to be the same as for the previous six-DoF tests to allow comparison of responses for uniaxial versus multiaxial excitations. The experimental results showed significant differences in the acceleration response of the mass as well as the strain measured in the beam. The modal participations were different for the multiaxial experiment, and the resulting instantaneous stresses and accelerations states were different, not only in magnitude, but also in location and direction. This indicated that the potential failure modes would be different.

\section{Mapping Dynamic Loads to Fatigue}

Some fatigue specialists maintain that the stress levels caused by vibration are usually too low to contribute to fatigue damage and that fatigue cracks start because of higher stresses present in the loading history [2]. It is also commonly known that the substantial number of stress cycles produced by highfrequency excitations can considerably contribute to fatigue damage and may cause failure without reaching high load levels [5, 134]. Special analysis is often required in these situations since the vibration data is not in a form that can be used directly in a common fatigue damage model 


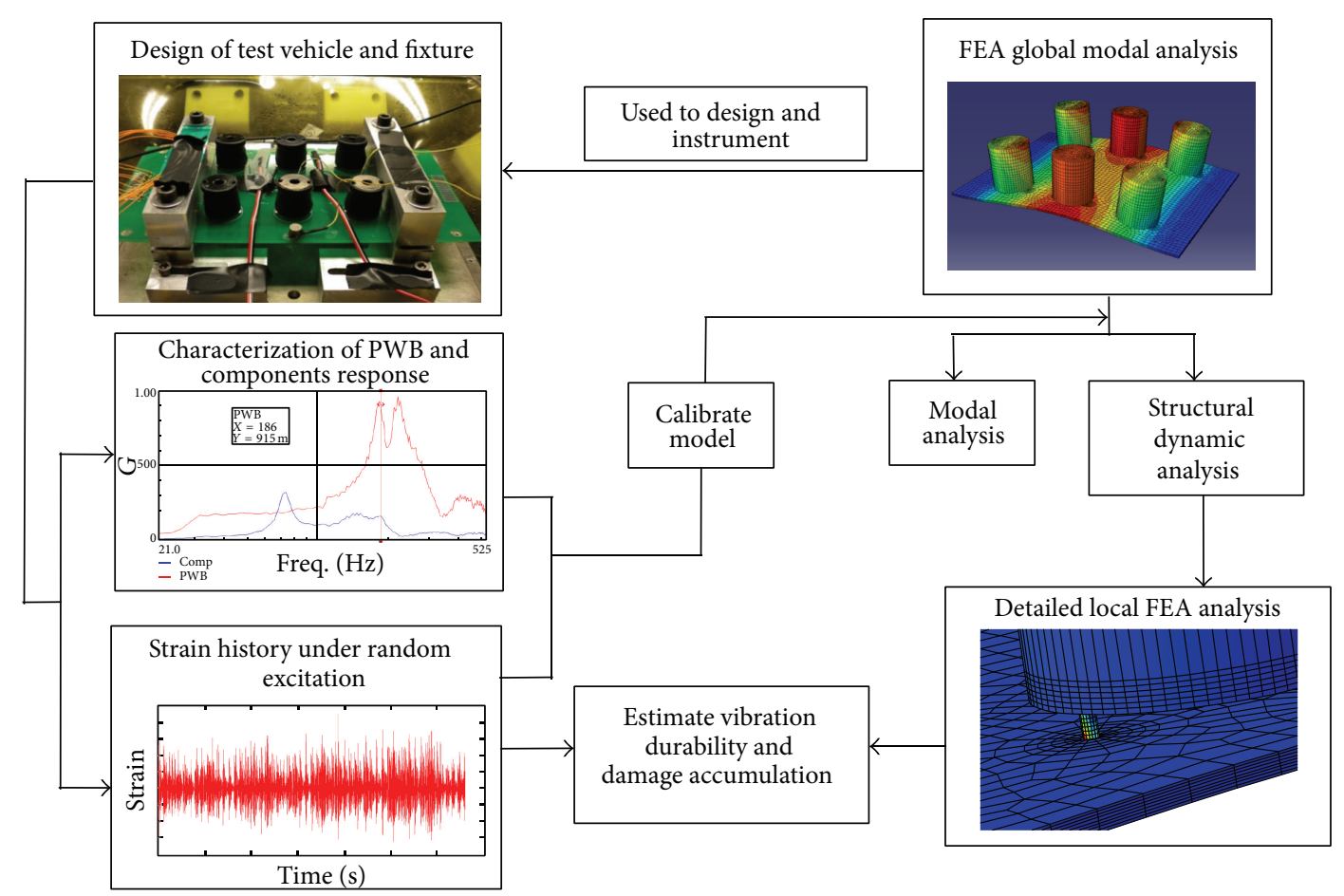

FIgURE 9: Approach for mapping dynamic loads to fatigue [136].

such as the Palmgren-Miner rule. A common approach in mapping stationary random dynamic loads to fatigue is through performing a summation of all modal spectral densities and determining the response standard deviations in a broadband frequency range, covering all resonance frequencies of the structure within broadband frequency range. The modal cross-spectral densities are typically neglected [135]. Nonetheless, Dahlberg states that lightly damped structures with well-separated fundamental frequencies are not a sufficient reason to neglect modal cross-spectral densities even if the random excitation of the structure is broadband where several modes of the structure are excited [135].

To accurately estimate multiaxial vibration durability and damage accumulation, the dynamics response model of the structure must be coupled with experimental data, as illustrated in Figure 9 [136]. This approach requires an iterative and arduous development. The reason for this is that the reaction forces and vibration velocities in complex structures depend not only on the strength of excitation, but also on the coupling between structures and their components, as shown in Figure 9. The computational and experimental coupling is necessary since the FEM cannot model structures adequately up to midfrequency range due to the higher modal density. The experimental tasks provide FRF dynamic characterization of the structure and its components as well as time history data. A more practical approach is to utilize the experimental FRF data to represent the structure and then combine it with the FEM models as shown in Figure 9. However, this approach is not applicable if the structure is exposed to high amplitude excitation that could generate nonlinear behavior. Thus, the time history data must be combined with the FEM models. This approach is intended to yield accurate results but is time consuming to set up and is computationally expensive.

Currently, the Center for Advanced Life Cycle Engineering (CALCE) at the University of Maryland and the US Army Research Laboratory (ARL) are investigating the utility of multiaxial electrodynamic shakers. The objective is to study the differences in failure modes and fatigue life for multiaxial versus single-axial excitations by utilizing multiaxial electrodynamic shakers. The multiaxial electrodynamic shaker used for this study was developed by TEAM Inc. It consists of eight plane actuators and four out-ofplane actuators underneath the shaker table, as shown in Figure 1. The twelve electrodynamic shakers are mechanically coupled to the table. This architecture allows the shaker to produce a true six-DoF vibration environment. Each axis has four shakers with $200 \mathrm{lbf}$ rotation per axis. The excitation limit is up to $30 \mathrm{Gs}$ with $0-3000 \mathrm{~Hz}$. The objective is to establish a quantitative and qualitative relationship between complex random multiaxial dynamic loading and the failure mechanisms. In this study, CALCE performed two sets of three random excitation experiments on CCAs. The first set was for low amplitude broadband stationary random excitations, which consisted of the following single-axis inplane, single-axis out-of-plane and combined in-plane and out-of-plane excitations. Each CCA was clamped along the two short edges while it was free along the two long edges, as shown in Figure 10. The CCA contained six large heavy inductors with high center of mass and with high standoff, as shown in Figure 10. Each inductor was attached to the CCA via two leads to instigate bending motion in the in-plane 


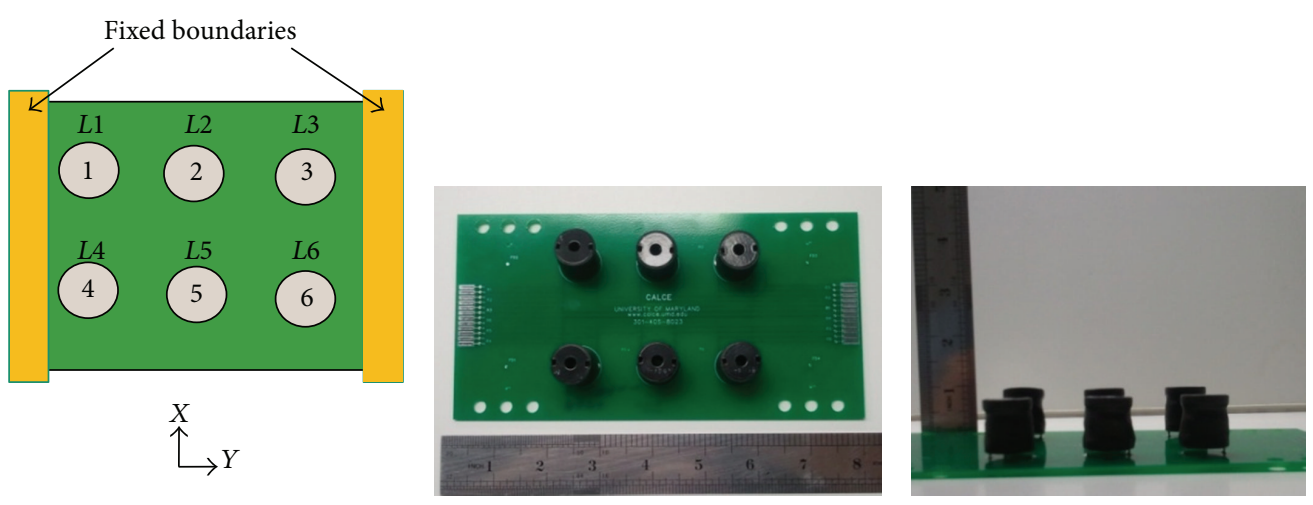

FIgURE 10: CCA with six large inductors, dimensions are in inches.

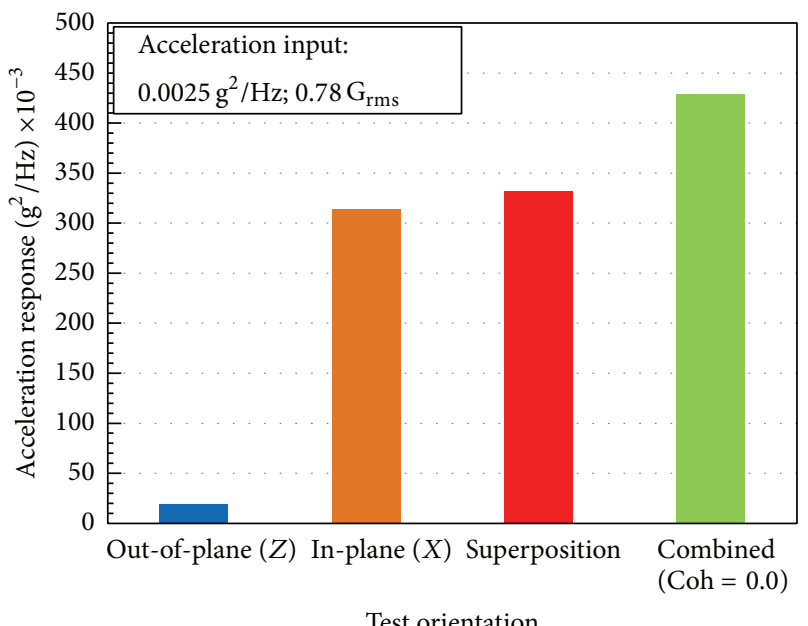

FIGURE 11: Component 2 acceleration response in the $x$-direction $0.78 \mathrm{G}_{\mathrm{rms}}$.

direction and a gyroscopic motion. In the first set of tests, the excitation was a uniform broadband random stationary profile at low PSD acceleration input of $0.0025 \mathrm{~g}^{2} / \mathrm{Hz}$ and $0.78 \mathrm{G}_{\mathrm{rms}}$.

The acceleration responses of the middle component for the three different excitations mentioned above are shown in Figure 11 and compared to the superposition technique. The same sets of tests were repeated for higher PSD acceleration input of $0.04 \mathrm{~g}^{2} / \mathrm{Hz}$ and $3.14 \mathrm{G}_{\mathrm{rms}}$. The acceleration responses in the in-plane direction $(X)$ of the middle component for the three different excitations mentioned above are shown in Figures 11 and 12 and compared to the superposition technique. Figures 11 and 12 show the component response due to multiaxial excitations is equivalent to the linear superposition of corresponding uniaxial responses. Furthermore, as the acceleration input increases, the deviation between the actual component response due to multiaxial vibration and the linear superposition of uniaxial responses increases as well. This deviation may be justified based on three reasons. First, the modal participation and nonlinear interactions between components and PWB could be the major contributors to

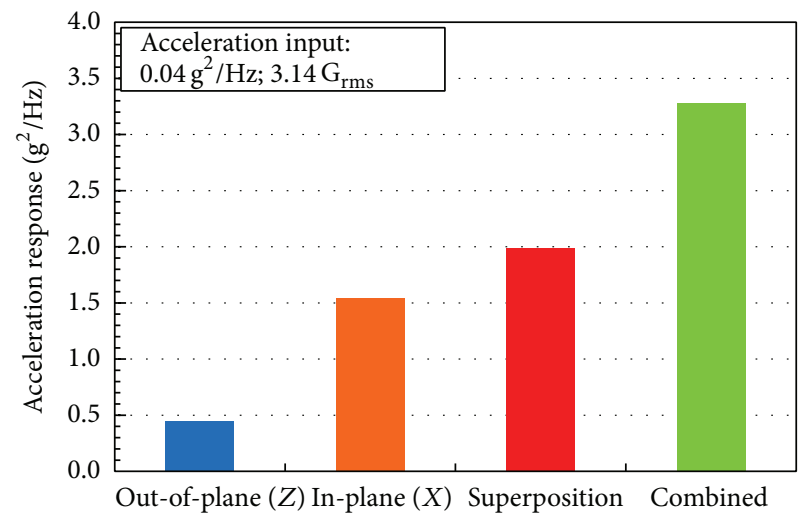

FIGURE 12: Component 2 acceleration response in the $x$-direction at $3.14 \mathrm{G}_{\mathrm{rms}}$.

this deviation. Second, the geometry of each component may create gyroscopic forces, which are proportional to the velocities consistent with viscous damping forces; however, they are conservative forces [137]. Finally, the material nonlinearity of the PWB and the solder joints may augment the drastic difference in TTF between multiaxial excitations and sequential uniaxial superposition, as shown in Figure 13. Further studies are needed to quantify these contributions.

The fatigue damage in the components' interconnects site, shown in Figure 14, is due to a combination of flexural deformations in PCBs and inertial forces (translation and gyroscopic motions). The inertial forces are generated by the mass of large/heavy components with high standoff. Thus, simultaneous multiaxial vibration may have the potential to generate higher stresses through nonlinear cross-axis interactions at the component level.

In this study, the change of the natural frequencies of a middle component (L5) and an edge component (L1) were monitored during the experiments mentioned above. Ernst et al. [49] showed that the frequencies shifted linearly across all components under single axial and biaxial vibration conditions, as shown in Figure 15. Ernst et al. assumed that this shift corresponded to fatigue crack growth in the component lead shown in Figure 14. Their results also revealed that natural frequency was lower when the CCA 


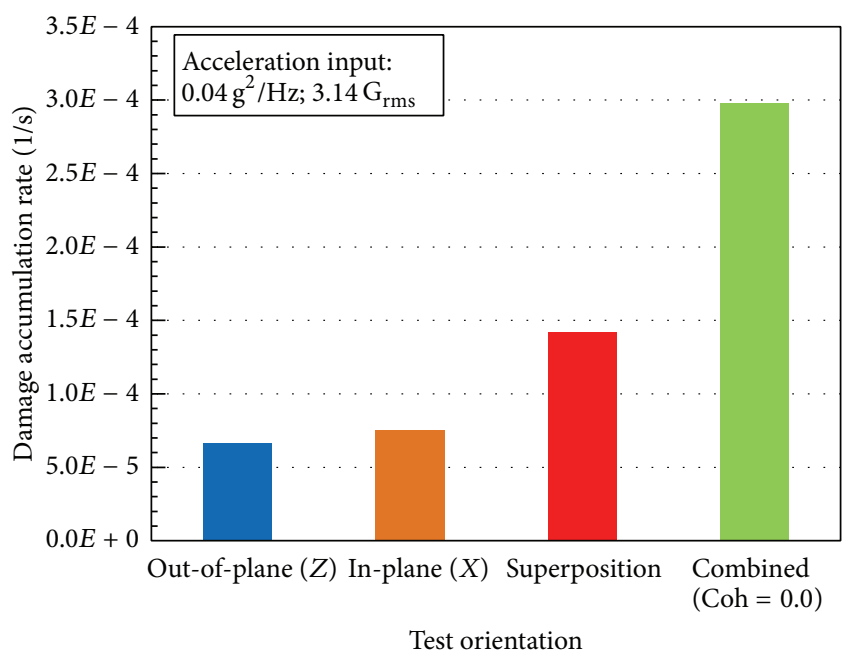

FIGURE 13: Component 2 damage accumulation rate at $3.14 \mathrm{G}_{\mathrm{rms}}$.

was exposed to multiaxial excitation, but they indicated that further investigation is needed to verify this phenomenon. Ernst et al. proposed using this approach as a possible method for failure prognostics and prediction for the components' remaining life. This approach has been observed in current studies exploring methods for improving accelerated fatigue testing by simultaneously monitoring the modal parameters of critical components [138-142].

\section{Future Directions}

Based on the literature review and interaction with government agencies, industries, and academia, the authors recognized three major thrust areas for continued research and deployment: modeling and simulation, experimental and testing, and standards and procedures updating. These thrust areas are summarized in Figure 16. As mentioned above, several closed-form solutions and computational models were developed to approximate the response and fatigue life of linear and nonlinear structures exposed to complex vibration loading. Most of these models are based on unique approximations and can only be applied to specific loading and boundary conditions. Some of these loading conditions were not possible to duplicate in a laboratory environment prior to the introduction of the multiaxial electrodynamic shaker capable of producing rotational degrees of freedoms. This capability is opening a plethora of opportunities to validate and update existing multibodies and flexible-bodies dynamic models and produce new realistic models to adequately approximate the response of structures and subsequently their remaining life. Analysts may be able to move beyond the laborious approach of conducting explicit FEM analysis calibrated with suspect transfer functions obtained from sequential testing, then following it by another explicit analysis based on time history data and comparing the strain results to those from testing. There might be a possibility for developing spectral FEM models to avoid using the cumbersome and expensive explicit FEM.

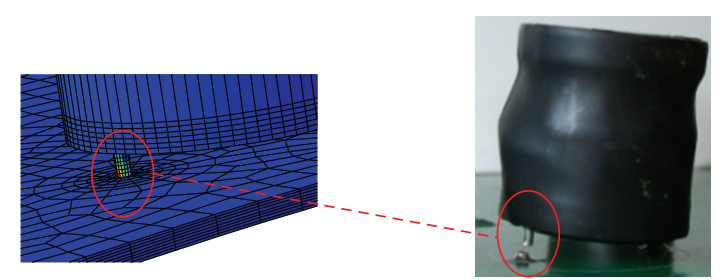

FIgURE 14: Component L2 failure due to in-plane and out-of-plane excitations at $3.14 \mathrm{G}_{\mathrm{rms}}$.

As shown above, CALCE/ARL has shown that simultaneous multiaxial vibration may have the potential to generate higher stresses through nonlinear cross-axis interactions at the component level. This was possible because of the capabilities that the MDoF electrodynamic shaker was able to provide. However, generating the loads for different complex operational conditions and tracking the structural response of critical components require significant signal processing, data reduction, and real-time computation of the inputs/outputs. Stochastic models may potentially be updated as a result of the coherent/incoherent multiaxial random vibration excitation that can be achieved with the MDoF electrodynamic technology. Accelerated test factors are currently incorporated in the MIL-STF-810G combined with exaggeration factors to provide conservatism in the uniaxial test schedules. Multiaxial vibration studies may provide insights into whether these factors are reasonable or not and provide new guidelines for accelerated life testing using MDoF technologies. Furthermore, the design for prognostic and diagnostics, structural health management and condition-based maintenance may be enhanced and ruggedized through real-world multiaxial dynamics laboratory simulations.

\section{Conclusion}

It can be concluded from this literature review that it is essential to understand the structural characteristics of devices in order to correlate the defects with the dynamic responses. As mentioned above, the main challenge in structural systems is the prediction of the reliability and lifetime of the critical components. Therefore, it is imperative to identify the failure mechanisms of the components through adequate computational and experimental analyses. However, the experimental and computational approaches must emulate the real-world operational conditions, which include simulating MDoF dynamic loads. This involves estimating and measuring the transient multiaxial displacements, which can be accomplished with the aid of a multiaxial shaker.

Establishing the relationship between different flexible structures formulations is an important issue since there is a need to clearly define the assumptions and approximations underlying each formulation. This may allow for establishing guidelines and criteria that define the limitations of each approach used in flexible structures dynamics. This task can now be accomplished by utilizing multiaxial vibration capability, which is making it possible to perform the 


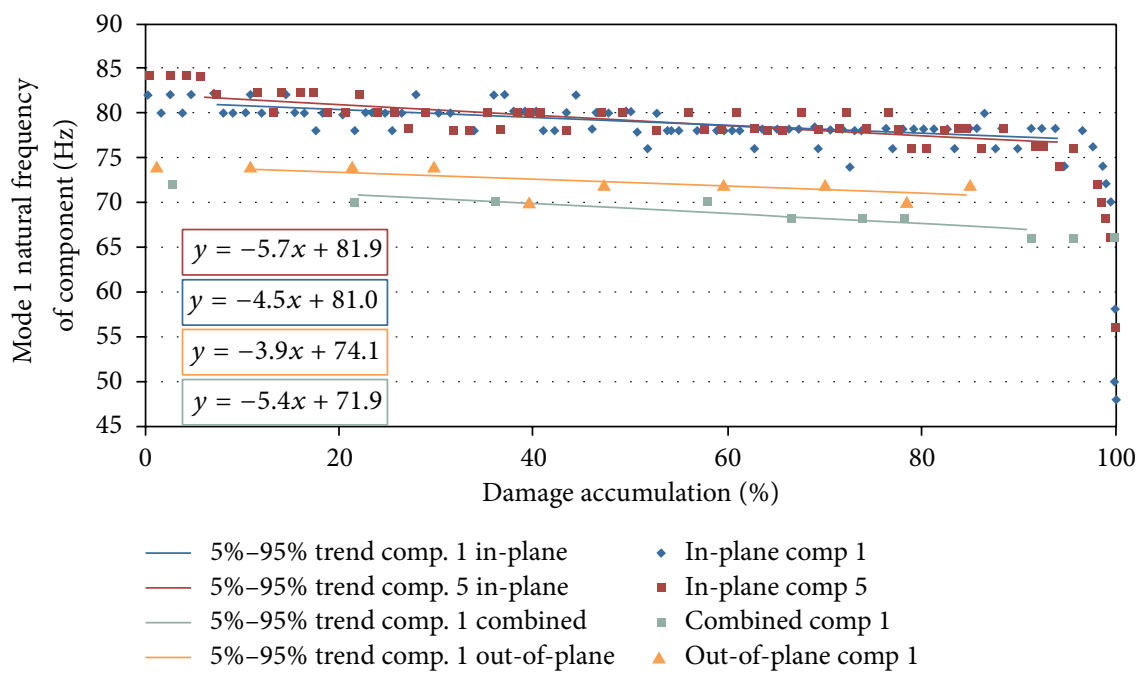

FIGURE 15: Change in the natural frequency as a function of damage accumulation [49].

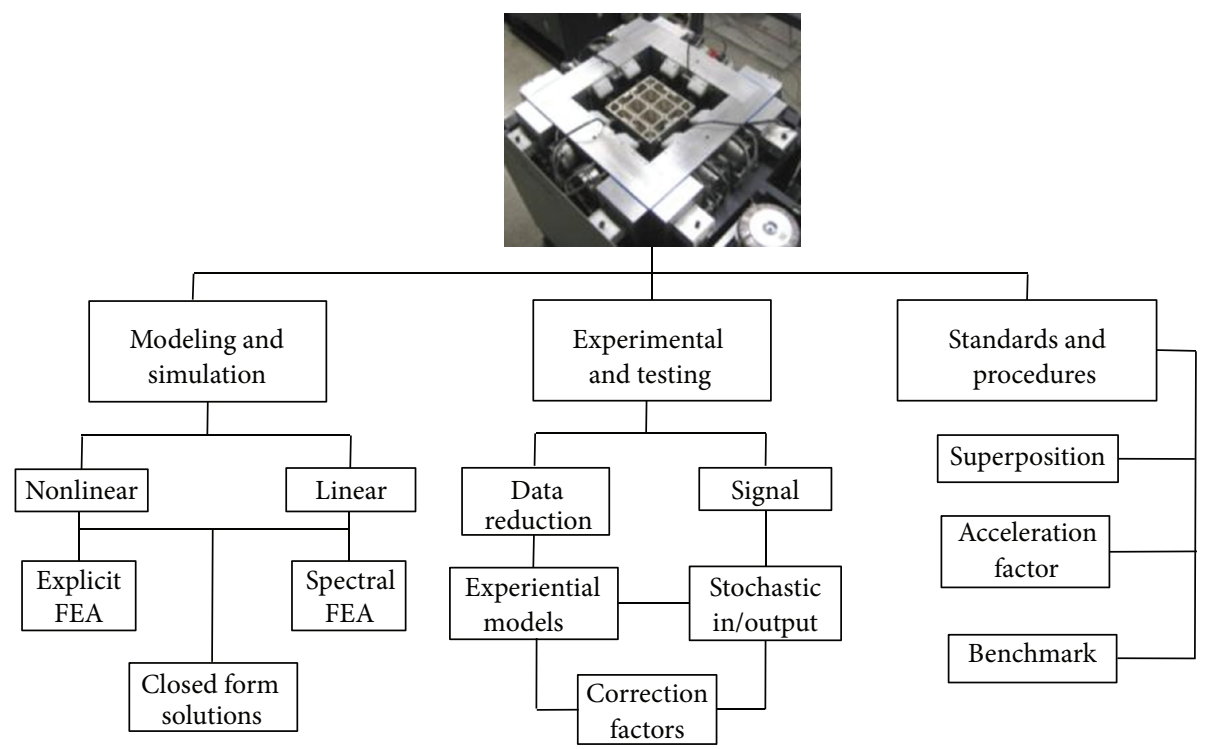

FIGURE 16: Research areas and potential gaps.

CALCE/ARL joint research efforts to study large deformation of flexible systems exposed to multiaxial excitations.

\section{Conflict of Interests}

The authors declare that there is no conflict of interests regarding the publication of this paper.

\section{Acknowledgments}

This work was accomplished via the Collaborative Research and Development Agreement (CRADA) between the US Army Research Laboratory and the University of Maryland, College Park, and the continual support of TEAM Inc. and DataPhysics Inc. The authors thank the sponsors of the
Center for Advanced Life Cycle Engineering (CALCE) for providing access to the MDoF shaker facility.

\section{References}

[1] J. E. Shigley and C. R. Mischke, Mechanical Engineering Design, McGraw-Hill, Boston, Mass, USA, 6th edition, 2001.

[2] N. E. Dowling, Mechanical Behavior of Materials: Engineering Methods for Deformation, Fracture, and Fatigue, Prentice Hall, Upper Saddle River, NJ, USA, 2nd edition, 1999.

[3] I. Elishakoff, "Generalized eringen problem: influence of axial force on random vibration response of simply supported beam," Structural Safety, vol. 4, no. 4, pp. 255-265, 1987.

[4] C. Leser, L. Juneja, S. Thangjitham, and N. E. Dowling, "On multi-axial random fatigue load modeling," SAE Technical Paper 980696, Society of Automotive Engineering, 1996. 
[5] Y. Liu and S. Mahadevan, "Multiaxial high-cycle fatigue criterion and life prediction for metals," International Journal of Fatigue, vol. 27, no. 7, pp. 790-800, 2005.

[6] X. Pitoiset, A. Preumont, and A. Kernilis, “Tools for a multiaxial fatigue analysis of structures submitted to random vibrations," in Proceedings of the European Conference on Spacecraft Structures Materials and Mechanical Testing, Braunschweig, Germany, November 1998.

[7] D. J. Segalman, C. W. G. Fulcher, G. M. Reese, and R. V. Field Jr., "Efficient method for calculating r.m.s. von Mises stress in a random vibration environment," Journal of Sound and Vibration, vol. 230, no. 2, pp. 393-410, 2000.

[8] D. Socie and G. Marquis, Multiaxial Fatigue, Society of Automotive Engineers, Warrendale, Pa, USA, 2000.

[9] K. A. Sweitzer, Random Vibration Response Statistics for Fatigue Analysis of Nonlinear Structures [Ph.D. thesis], University of Southampton, Southampton, UK, 2006.

[10] W. E. Whiteman and M. S. Berman, "Fatigue failure results for multi-axial versus uniaxial stress screen vibration testing," Shock and Vibration, vol. 9, no. 6, pp. 319-328, 2002.

[11] M. Paulus, A. Dasgupta, and E. Habtour, "Life estimation model of a cantilevered beam subjected to complex random vibration," Fatigue and Fracture of Engineering Materials and Structures, vol. 35, no. 11, pp. 1058-1070, 2012.

[12] R. M. French, R. Handy, and H. L. Cooper, "A comparison of simultaneous and sequential single-axis durability testing," Experimental Techniques, vol. 30, no. 5, pp. 32-37, 2006.

[13] W. E. Whiteman and M. Berman, "Inadequacies in uniaxial stress screen vibration testing," Journal of the Institute of Environmental Sciences and Technology, vol. 44, no. 4, pp. 2023, 2001.

[14] E. Habtour, C. Choi, G. Drake, A. Dasgupta, and M. AlBassyiouni, "Improved reliability testing with multiaxial electrodynamics vibration," in Proceedings of the 56th Annual Reliability and Maintainability Symposium, San Jose, Calif, USA, 2010.

[15] E. Habtour, C. Choi, M. Osterman, and A. Dasgupta, "Novel approach to improve electronics reliability in the next generation of US army small unmanned ground vehicles under complex vibration conditions," Journal of Failure Analysis and Prevention, vol. 12, no. 1, pp. 86-95, 2012.

[16] C. J. Dodds and C. H. Ward, "The ubiquitous four-poster," Engineering Integrity Society, vol. 16, no. 1, pp. 17-23, 2005.

[17] C. M. Awate, S. M. Panse, and C. J. Dodds, "Validation of an accelerated test on a four-post road simulator," Paper 2007-26070, Society of Automotive Engineering, pp. 761-767, 2007.

[18] C. J. Dodds and A. R. Plummer, "Laboratory road simulation for full vehicle testing a review," in Proceedings of the Symposium on International Automotive Technology, 2001.

[19] J. C. Delamotte, R. F. Nascimento, and J. R. F. Arruda, "Simple models for the dynamic modeling of rotating tires," Shock and Vibration, vol. 15, no. 3-4, pp. 383-393, 2008.

[20] C. Q. Liu, "Combination of an improved FRF-based substructure synthesis and power flow method with application to vehicle axle noise analysis," Shock and Vibration, vol. 15, no. 1, pp. 51-60, 2008.

[21] N. W. M. Bishop, "Vibration fatigue analysis in the finite element environment," in Proceedings of the 16th Encuentro del Grupo Español de Fractura, Torremolinos, Spain, 1999.

[22] M. H. A. Bonte, A. De Boer, and R. Liebregts, "Prediction of mechanical fatigue caused by multiple random excitations," in
Proceedings of the ISMA Conference, pp. 697-708, September 2004.

[23] M. H. A. Bonte, A. de Boer, and R. Liebregts, "Determining the von Mises stress power spectral density for frequency domain fatigue analysis including out-of-phase stress components," Journal of Sound and Vibration, vol. 302, no. 1-2, pp. 379-386, 2007.

[24] P. H. Wirsching, T. L. Paez, and K. Ortiz, Random Vibrations: Theory and Practice, John Wiley and Sons, New York, NY, USA, 1995.

[25] T. Dirlik, Application of Computers in Fatigue Analysis [Ph.D. thesis], University of Warwick, Warwick, UK, 1985.

[26] D. A. Thomas, K. Avers, and M. Pecht, "The "trouble not identified" phenomenon in automotive electronics," Microelectronics Reliability, vol. 42, no. 4-5, pp. 641-651, 2002.

[27] D. H. Hodges and G. A. Pierce, Introduction to Structural Dynamics and Aeroelasticity, 2nd edition, 2011.

[28] J. M. Sater, C. R. Crowe, R. Antcliff, and A. Das, "An assessment of smart Air and space structures: demonstrations and technology," IDA Report P-3552, Log: H 00-002035, Institute for Defense Analysis, Alexandria, Va, USA, 2000.

[29] M. R. M. C. Da Silva, "Non-linear flexural-flexural-torsionalextensional dynamics of beams-I. Formulation," International Journal of Solids and Structures, vol. 24, no. 12, pp. 1225-1234, 1988.

[30] M. R. M. Crespo Da Silva and C. L. Zaretzky, "Nonlinear flexural-flexural-torsional interactions in beams including the effect of torsional dynamics. I: primary resonance," Nonlinear Dynamics, vol. 5, no. 1, pp. 3-23, 1994.

[31] E. H. Dowell, "Damping in beams and plates due to slipping at the support boundaries," Journal of Sound and Vibration, vol. 105, no. 2, pp. 243-253, 1986.

[32] D. H. Hodges and E. H. Dowell, "Nonlinear equations of motion for the elastic bending and torsion of twisted nonuniform rotor blades," NASA Technical Notes NASA TN D-7818, 1974.

[33] D. S. Whithead, "The analysis of blade vibration due to random excitation,” Tech. Rep. 3253, United Kingdom Ministry of Aviation: Aeronautical Research Council Reports and Memoranda, London, UK, 1960.

[34] M. Aykan and M. Çelik, "Vibration fatigue analysis and multiaxial effect in testing of aerospace structures," Mechanical Systems and Signal Processing, vol. 23, no. 3, pp. 897-907, 2009.

[35] G. V. Chary, E. Habtour, and G. S. Drake, "Improving the reliability in the next generation of US army platforms through physics of failure analysis," Journal of Failure Analysis and Prevention, vol. 12, no. 1, pp. 75-58, 2012.

[36] Y. Zhou, M. Al-Bassyiouni, and A. Dasgupta, "Vibration durability assessment of sn3.0ag0.5cu and sn $37 \mathrm{pb}$ solders under harmonic excitation," Journal of Electronic Packaging, vol. 131, no. 1, 2009.

[37] J. H. Lau, Solder Joint Reliability, Theory and Applications, Van Nostrand Reinhold, New York, NY, USA, 1990.

[38] J. Lau, K. Gratalo, E. Schneider, T. Marcotte, and T. Baker, "Solder joint reliability of large plastic ball grid array assemblies under bending, twisting, and vibration conditions," Circuit World, vol. 22, no. 1, pp. 27-32, 1995.

[39] J. H. Lau and P. Yi, Solder Joint Reliability, of BGA, CSP, Flip Chip and Fine Pitch SMT Assemblies, McGraw-Hill, New York, NY, USA, 1997.

[40] X. Liu, V. K. Sooklal, M. A. Verges, and M. C. Larson, "Experimental study and life prediction on high cycle vibration 
fatigue in BGA packages," Microelectronics Reliability, vol. 46, no. 7, pp. 1128-1138, 2006.

[41] X. Yang, Y. Luo, and Q. Gao, "Constitutive modeling on time-dependent deformation behavior of $96.5 \mathrm{Sn}$-3.5Ag solder alloy under cyclic multiaxial straining," Journal of Electronic Packaging, vol. 129, no. 1, pp. 41-47, 2007.

[42] Y. Zhou, M. Al-Bassyiouni, and A. Dasgupta, "Harmonic and random vibration durability of SAC305 and $\mathrm{Sn} 37 \mathrm{~Pb}$ solder alloys," IEEE Transactions on Components and Packaging Technologies, vol. 33, no. 2, pp. 319-328, 2010.

[43] J. Gu, D. Barker, and M. Pecht, "Prognostics implementation of electronics under vibration loading," Microelectronics Reliability, vol. 47, no. 12, pp. 1849-1856, 2007.

[44] D. B. Barker, Y. S. Chen, and A. Dasgupta, "Estimating the vibration fatigue life of quad leaded surface mount components," Journal of Electronic Packaging, vol. 115, no. 2, pp. 195-200, 1993.

[45] R. S. Li, "A methodology for fatigue prediction of electronic components under random vibration load," Journal of Electronic Packaging, vol. 123, no. 4, pp. 394-400, 2001.

[46] E. Martynenko, W. Zhou, A. Chudnovsky, R. S. Li, and L. Poglitsch, "High cycle fatigue resistance and reliability assessment of flexible printed circuitry," Journal of Electronic Packaging, vol. 124, no. 3, pp. 254-259, 2002.

[47] S. Mathew, D. Das, M. Osterman, M. Pecht, R. Ferebee, and J. Clayton, "Virtual remaining life assessment of electronic hardware subjected to shock and random vibration life cycle loads," Journal of the Institute of Environmental Sciences and Technology, vol. 50, no. 1, pp. 86-97, 2007.

[48] S. Shetty, V. Lehtinen, A. Dasgupta, V. Halkola, and T. Reinikainen, "Fatigue of chip scale package interconnects due to cyclic bending," Journal of Electronic Packaging, vol. 123, no. 3, pp. 302-308, 2001.

[49] M. Ernst, C. Choi, A. Dasgupta, and E. Habtour, "Physics of failure models for multiaxial vibration fatigue in electronics assemblies," in Proceedings of the Accelerated Stress Testing and Reliability Workshop, Ontario, Canada, 2012.

[50] A. C. Eringen, "Response of beams and to random loads," Journal of Applied Mechanics, vol. 24, pp. 46-52, 1957.

[51] R. E. Herbert, "Random vibrations of a nonlinear elastic beam," Journal of the Acoustical Society of America, vol. 36, no. 11, pp. 2090-2094, 1964.

[52] I. Elishakoff and D. Livshits, "Some closed-form solutions in random vibration of Bernoulli-Euler beams," International Journal of Engineering Science, vol. 22, no. 11-12, pp. 1291-1301, 1984.

[53] I. Elishakoff, J. Fang, and R. Caimi, "Random vibration of a nonlinearly deformed beam by a new stochastic linearization technique," International Journal of Solids and Structures, vol. 32, no. 11, pp. 1571-1584, 1995.

[54] R. A. Ibrahim and R. J. Somnay, "Nonlinear dynamic analysis of an elastic beam isolator sliding on frictional supports," Journal of Sound and Vibration, vol. 308, no. 3-5, pp. 735-757, 2007.

[55] C.-H. Ho, R. A. Scott, and J. G. Eisley, "Non-planar, non-linear oscillations of a beam-I. Forced motions," International Journal of Non-Linear Mechanics, vol. 10, no. 2, pp. 113-127, 1975.

[56] C.-H. Ho, R. A. Scott, and J. G. Eisley, "Non-planar, non-linear oscillations of a beam II. Free motions," Journal of Sound and Vibration, vol. 47, no. 3, pp. 333-339, 1976.

[57] M. R. M. Crespo da Silva and C. C. Glynn, "Nonlinear flexural-flexural-torsional dynamics of inextensional beams. I: equations of motion," Journal of Structural Mechanics, vol. 6, no. 4, pp. 437-448, 1978.
[58] M. R. M. Crespo de Silva and C. C. Glynn, "Nonlinear flexuralflexural-torsional dynamics of inextensional beams. II: forced motions," Journal of Structural Mechanics, vol. 6, no. 4, pp. 449461, 1978.

[59] M. R. M. C. Da Silva, "Non-linear flexural-flexural-torsionalextensional dynamics of beams-II. Response analysis," International Journal of Solids and Structures, vol. 24, no. 12, pp. 12351242, 1988.

[60] A. H. Nayfeh and P. F. Pai, "Non-linear non-planar parametric responses of an inextensional beam," International Journal of Non-Linear Mechanics, vol. 24, no. 2, pp. 139-158, 1989.

[61] P. F. Pai and A. H. Nayfeh, "Non-linear non-planar oscillations of a cantilever beam under lateral base excitations," International Journal of Non-Linear Mechanics, vol. 25, no. 5, pp. 455474, 1990.

[62] C. L. Zaretzky and M. R. M. Crespo da Silva, "Nonlinear flexural-flexural-torsional interactions in beams including the effect of torsional dynamics. II: combination resonance," Nonlinear Dynamics, vol. 5, no. 2, pp. 161-180, 1994.

[63] H. N. Arafat, A. H. Nayfeh, and C.-M. Chin, "Nonlinear nonplanar dynamics of parametrically excited cantilever beams," Nonlinear Dynamics, vol. 15, no. 1, pp. 31-61, 1998.

[64] A. H. Nayfeh and H. N. Arafat, "Investigation of subcombination internal resonances in cantilever beams," Shock and Vibration, vol. 5, pp. 289-296, 1998.

[65] A. H. Nayfeh and H. N. Arafat, "Nonlinear response of cantilever beams to combination and subcombination resonances," Shock and Vibration, vol. 5, no. 5-6, pp. 277-288, 1998.

[66] H. N. Arafat, Nonlinear Dynamic Analysis of Cantilever Beam [Ph.D. thesis], Virginia Polytechnic Institute and State University, Blacksburg, Va, USA, 1999.

[67] J. R. Banerjee, "Explicit analytical expressions for frequency equation and mode shapes of composite beams," International Journal of Solids and Structures, vol. 38, no. 14, pp. 2415-2426, 2001.

[68] P. Malatkar and A. H. Nayfeh, "On the transfer of energy between widely spaced modes in structures," Nonlinear Dynamics, vol. 31, no. 2, pp. 225-242, 2003.

[69] P. Malatkar and A. H. Nayfeh, "A parametric identification technique for single-degree-of-freedom weakly nonlinear systems with cubic nonlinearities," Journal of Vibration and Control, vol. 9, no. 3-4, pp. 317-336, 2003.

[70] P. Malatkar, Nonlinear Vibrations of Cantilever Beams and Plates [Ph.D. thesis], Virginia Polytechnic Institute and State University, Blacksburg, Va, USA, 2003.

[71] T. J. Anderson, B. Balachandran, and A. H. Nayfeh, "Nonlinear resonances in a flexible cantilever beam," Journal of Vibration and Acoustics, vol. 116, no. 4, pp. 480-484, 1994.

[72] J. Dugundji and V. Mukhopadhyay, "Lateral bending-torsion vibrations of a thin beam under parametric excitation," Journal of Applied Mechanics, vol. 40, no. 3, pp. 693-698, 1973.

[73] D. M. Tang and E. H. Dowell, "Damping in beams and plates due to slipping at the support boundaries. Part 2: numerical and experimental study," Journal of Sound and Vibration, vol. 108, no. 3, pp. 509-522, 1986.

[74] C. W. S. To, "Vibration of a cantilever beam with a base excitation and tip mass," Journal of Sound and Vibration, vol. 83, no. 4, pp. 445-460, 1982.

[75] M. P. Cartmell and J. W. Roberts, "Simultaneous combination resonances in a parametrically excited cantilever beam," Strain, vol. 23, no. 3, pp. 117-126, 1987. 
[76] B. Balachandran and A. H. Nayfeh, "Nonlinear motions of beam-mass structure," Nonlinear Dynamics, vol. 1, no. 1, pp. 3961, 1990.

[77] B. Balachandran and A. H. Nayfeh, "Observations of modal interactions in resonantly forced beam-mass structures," Nonlinear Dynamics, vol. 2, no. 2, pp. 77-117, 1991.

[78] J. W. Jaworski and E. H. Dowell, "Free vibration of a cantilevered beam with multiple steps: comparison of several theoretical methods with experiment," Journal of Sound and Vibration, vol. 312, no. 4-5, pp. 713-725, 2008.

[79] M. Ansari, E. Esmailzadeh, and N. Jalili, "Coupled vibration and parameter sensitivity analysis of rocking-mass vibrating gyroscopes," Journal of Sound and Vibration, vol. 327, no. 3-5, pp. 564-583, 2009.

[80] A. M. Wickenheiser, "Design optimization of linear and nonlinear cantilevered energy harvesters for broadband vibrations," Journal of Intelligent Material Systems and Structures, vol. 22, no. 11, pp. 1213-1225, 2011.

[81] M. Ansari, E. Esmailzadeh, and N. Jalili, "Exact frequency analysis of a rotating cantilever beam with tip mass subjected to torsional-bending vibrations," Journal of Vibration and Acoustics, vol. 133, no. 4, Article ID 041003, 2011.

[82] A. Erturk and D. J. Inman, "Parameter identification and optimization in piezoelectric energy harvesting: analytical relations, asymptotic analyses, and experimental validations," Proceedings of the Institution of Mechanical Engineers. Part I: Journal of Systems and Control Engineering, vol. 225, no. 4, pp. 485-496, 2011.

[83] A. Erturk, "Assumed-modes modeling of piezoelectric energy harvesters: euler-bernoulli, rayleigh, and timoshenko models with axial deformations," Computers and Structures, vol. 106107, pp. 214-227, 2012.

[84] M. Esmaeili, N. Jalili, and M. Durali, "Dynamic modeling and performance evaluation of a vibrating beam microgyroscope under general support motion," Journal of Sound and Vibration, vol. 301, no. 1-2, pp. 146-164, 2007.

[85] S. C. Stanton, C. C. McGehee, and B. P. Mann, "Nonlinear dynamics for broadband energy harvesting: investigation of a bistable piezoelectric inertial generator," Physica D: Nonlinear Phenomena, vol. 239, no. 10, pp. 640-653, 2010.

[86] C. P. Green and J. E. Sader, “Torsional frequency response of cantilever beams immersed in viscous fluids with applications to the atomic force microscope," Journal of Applied Physics, vol. 92, no. 10, pp. 6262-6274, 2002.

[87] S. C. Stanton, A. Erturk, B. P. Mann, E. H. Dowell, and D. J. Inman, "Nonlinear nonconservative behavior and modeling of piezoelectric energy harvesters including proof mass effects," Journal of Intelligent Material Systems and Structures, vol. 23, no. 2, pp. 183-199, 2012.

[88] S. C. Stanton, B. A. M. Owens, and B. P. Mann, "Harmonic balance analysis of the bistable piezoelectric inertial generator," Journal of Sound and Vibration, vol. 331, no. 15, pp. 3617-3627, 2012.

[89] H. J. R. Westra, D. M. Karabacak, S. H. Brongersma, M. CregoCalama, H. S. J. Van Der Zant, and W. J. Venstra, "Interactions between directly- and parametrically-driven vibration modes in a micromechanical resonator," Physical Review B: Condensed Matter and Materials Physics, vol. 84, no. 13, Article ID 134305, 2011.
[90] K. Wolf and O. Gottlieb, "Nonlinear dynamics of a cantilever beam actuated by piezoelectric layers in symmetric and asymmetric configuration," Tech. Rep. ETR-2001-02, Institute of Technology, Haifa, Israel, 2001.

[91] L. G. Villanueva, R. B. Karabalin, M. H. Matheny, D. Chi, J. E. Sader, and M. L. Roukes, "Nonlinearity in nanomechanical cantilevers," Physical Review B, vol. 87, Article ID 024304, 2013.

[92] V. Kumar, J. K. Miller, and J. F. Rhoads, "Nonlinear parametric amplification and attenuation in a base-excited cantilever beam," Journal of Sound and Vibration, vol. 330, no. 22, pp. 54015409, 2011.

[93] J. F. Rhoads, N. J. Miller, S. W. Shaw, and B. F. Feeny, "Mechanical domain parametric amplification," Journal of Vibration and Acoustics, vol. 130, no. 6, Article ID 061006, 2008.

[94] S. F. Ali, S. Adhikari, M. I. Friswell, and S. Narayanan, "The analysis of piezomagnetoelastic energy harvesters under broadband random excitations," Journal of Applied Physics, vol. 109, no. 7, Article ID 074904, 2011.

[95] G. Wu, H. Ji, K. Hansen et al., "Origin of nanomechanical cantilever motion generated from biomolecular interactions," Proceedings of the National Academy of Sciences of the United States of America, vol. 98, no. 4, pp. 1560-1564, 2001.

[96] K. S. Hwang, J. H. Lee, J. Park, D. S. Yoon, J. H. Park, and T. S. $\mathrm{Kim}$, "In-situ quantitative analysis of a prostate-specific antigen (PSA) using a nanomechanical PZT cantilever," Lab on a Chip: Miniaturisation for Chemistry and Biology, vol. 4, no. 6, pp. 547552, 2004.

[97] J. Dorignac, A. Kalinowski, S. Erramilli, and P. Mohanty, "Dynamical response of nanomechanical oscillators in immiscible viscous fluid for in Vitro biomolecular Recognition," Physical Review Letters, vol. 96, no. 18, Article ID 186105, 2006.

[98] A. Salehi-Khojin, S. Bashash, and N. Jalili, "Modeling and experimental vibration analysis of nanomechanical cantilever active probes," Journal of Micromechanics and Microengineering, vol. 18, no. 8, Article ID 085008, 2008.

[99] V. Seena, A. Fernandes, P. Pant, S. Mukherji, and V. Ramgopal Rao, "Polymer nanocomposite nanomechanical cantilever sensors: material characterization, device development and application in explosive vapour detection," Nanotechnology, vol. 22, no. 29, Article ID 295501, 2011.

[100] S. Suresh, Fatigue of Materials, Cambridge University Press, Cambridge, UK, 2nd edition, 1998.

[101] D. Segalman, G. Reese, R. Field Jr., and C. Fulcher, "Estimating the probability distribution of von Mises stress for structures undergoing random excitation," Journal of Vibration and Acoustics, vol. 122, no. 1, pp. 42-48, 2000.

[102] S. Sarkani, D. P. Kihl, and J. E. Beach, "Fatigue of welded joints under narrowband non-Gaussian loadings," Probabilistic Engineering Mechanics, vol. 9, no. 3, pp. 179-190, 1994.

[103] D. Radaj, C. M. Sonsino, and W. Fricke, Fatigue Assessment of Welded Joints By Local Approaches, Woodhead Publishing Limited, Cambridge, UK, 2006.

[104] A. Z. Palmgren, “Die Lebensdauer Von Kugellagern,” Zeitschriyt Des Vereines Der Deutschen Ingenioeren, vol. 68, pp. 339-341, 1924.

[105] M. A. Miner, “Cumulative damage in fatigue," Journal of Applied Mechanics, vol. 12, no. 3, pp. 159-164, 1945.

[106] J. W. Miles, "On structural fatigue under random loading," Journal of the Aeronautical Sciences, vol. 21, no. 11, pp. 753-762, 1957. 
[107] S. H. Crandall, "Zero crossings, peaks, and other statistical measures of random responses," Journal of the Acoustical Society of America, vol. 35, no. 11, pp. 1693-1699, 1963.

[108] Y. K. Lin, "Probability distributions of stress peaks in linear and nonlinear structures," AIAA Journal, vol. 1, no. 5, pp. 1133-1138, 1963.

[109] J. S. Bendat, "Probability functions for random responsesprediction of peaks, fatigue damage, and catastrophic failures," NASA CR-33, N64-17990, 1964.

[110] S. O. Rice, "Mathematical analysis of random noise," Selected Papers on Noise and Stochastic Processes, Dover, New York, NY, USA, 1954.

[111] N. W. M. Bishop, The Use of Frequency Domain Parameters to Predict Structural Fatigue [Ph.D. thesis], University of Warwick, 1988.

[112] N. W. M. Bishop and F. Sherratt, "Theoretical solution for the estimation of "rainflow" ranges from power spectral density data," Fatigue and Fracture of Engineering Materials and Structures, vol. 13, no. 4, pp. 311-326, 1990.

[113] K. Upadhyayula and A. Dasgupta, "Physics-of-failure guidelines for accelerated qualification of electronic systems," Quality and Reliability Engineering International, vol. 14, no. 6, pp. 433-447, 1998.

[114] E. Habtour, M. Paulus, and A. Dasgupta, "Modeling approach for predicting the rate of frequency change of notched beam exposed to Gaussian random excitation," Shock and Vibration, 2013.

[115] Y. Lu, Random Vibration Analysis of Higher-Order Nonlinear Beams and Composite Plates with Applications of ARMA Models [Ph.D. thesis], Virginia Polytechnic Institute and State University, Blacksburg, Va, USA, 2008.

[116] T. Łagoda, E. Macha, and A. Niesłony, "Fatigue life calculation by means of the cycle counting and spectral methods under multiaxial random loading," Fatigue and Fracture of Engineering Materials and Structures, vol. 28, no. 4, pp. 409-420, 2005.

[117] X. Pitoiset and A. Preumont, "Spectral methods for multiaxial random fatigue analysis of metallic structures," International Journal of Fatigue, vol. 22, no. 7, pp. 541-550, 2000.

[118] X. Pitoiset, I. Rychlik, and A. Preumont, "Spectral methods to estimate local multiaxial fatigue failure for structures undergoing random vibrations," Fatigue and Fracture of Engineering Materials and Structures, vol. 24, no. 11, pp. 715-727, 2001.

[119] A. Carpinteri, E. Macha, R. Brighenti, and A. Spagnoli, "Expected principal stress directions under multiaxial random loading. Part I: theoretical aspects of the weight function method," International Journal of Fatigue, vol. 21, no. 1, pp. 8388, 1999.

[120] A. Carpinteri, R. Brighenti, E. Macha, and A. Spagnoli, "Expected principal stress directions under multiaxial random loading. Part II: numerical simulation and experimental assessment through the weight function method," International Journal of Fatigue, vol. 21, no. 1, pp. 89-96, 1999.

[121] Y. Liu and S. Mahadevan, "A unified multiaxial fatigue damage model for isotropic and anisotropic materials," International Journal of Fatigue, vol. 29, no. 2, pp. 347-359, 2007.

[122] Y. Liu, Stochastic Modeling of Multiaxial Fatigue and Fracture [Ph.D. thesis], Vanderbilt University, Nashville, Tenn, USA, 2006.

[123] S. Lambert, E. Pagnacco, and L. Khalij, "A probabilistic model for the fatigue reliability of structures under random loadings with phase shift effects," International Journal of Fatigue, vol. 32, no. 2, pp. 463-474, 2010.
[124] C. Braccesi, F. Cianetti, G. Lori, and D. Pioli, "An equivalent uniaxial stress process for fatigue life estimation of mechanical components under multiaxial stress conditions," International Journal of Fatigue, vol. 30, no. 8, pp. 1479-1497, 2008.

[125] C. Braccesi, F. Cianetti, G. Lori, and D. Pioli, "The frequency domain approach in virtual fatigue estimation of non-linear systems: the problem of non-Gaussian states of stress," International Journal of Fatigue, vol. 31, no. 4, pp. 766-775, 2008.

[126] G. Allegri and X. Zhang, "On the inverse power laws for accelerated random fatigue testing," International Journal of Fatigue, vol. 30, no. 6, pp. 967-977, 2008.

[127] Z. Lei and C. Qiu, "A dynamic stochastic finite element method based on dynamic constraint mode," Computer Methods in Applied Mechanics and Engineering, vol. 161, no. 3-4, pp. 245255, 1998.

[128] S. I. McNeill, "A method for determining the fatigue critical plane for biaxial random vibration in the frequency domain: technical Note," Fatigue and Fracture of Engineering Materials and Structures, vol. 33, no. 6, pp. 390-394, 2010.

[129] T. Lagoda, E. Macha, and W. Będkowski, "Critical plane approach based on energy concepts: application to biaxial random tension-compression high-cycle fatigue regime," International Journal of Fatigue, vol. 21, no. 5, pp. 431-443, 1999.

[130] P. A. Tibbits, "Application of algorithms for percentiles of von mises stress from combined random vibration and static loadings," Journal of Vibration and Acoustics, vol. 133, no. 4, Article ID 044502, 2011.

[131] H. Guechichi, S. Benkabouche, A. Amrouche, and M. Benkhettab, "A high fatigue life prediction methodology under constant amplitude multiaxial proportional loadings," Materials Science and Engineering A, vol. 528, no. 13-14, pp. 4789-4798, 2011.

[132] D. Gregory, F. Bitsy, and D. O. Smallwood, "Comparison of the response of a simple structure to single axis and multiple axis random vibration inputs," in Proceedings of the 79th Shock and Vibration Symposium, Orlando, Fla, USA, 2008.

[133] U. Füllekrug, "Utilization of multi-axial shaking tables for the modal identification of structures," Philosophical Transactions of the Royal Society A: Mathematical, Physical and Engineering Sciences, vol. 359, no. 1786, pp. 1753-1770, 2001.

[134] D. E. Newland, An Introduction to Random Vibrations, Spectral and Wavelet Analysis, Dover, Mineola, NY, USA, 2005.

[135] T. Dahlberg, "The effect of modal coupling in random vibration analysis," Journal of Sound and Vibration, vol. 228, no. 1, pp. 157176, 1999.

[136] E. Habtour, M. Pohland, and A. Dasgupta, "Dynamic characterization of circuit card assemblies using multi-degree-offreedom random vibration," in Proceedings of the Accelerated Stress Testing and Reliability Workshop, San Francisco, Calif, USA, 2011.

[137] L. Meirovitch, Principles and Techniques of Vibrations, Prentice Hall, Upper Saddel River, NJ, USA, 1997.

[138] M. Cesnik, J. Slavic, and M. Boltezar, "Uninterrupted and accelerated vibrational fatigue testing with simultaneous monitoring of the natural frequency and damping," Journal of Sound and Vibration, vol. 331, pp. 5370-5382, 2012.

[139] A. Perkins and S. K. Sitaraman, "Analysis and prediction of vibration-induced solder joint failure for a ceramic column grid array package," Journal of Electronic Packaging, vol. 130, no. 1, 2008.

[140] C. Rainieri, G. Fabbrocino, and E. Cosenza, "Near real-time tracking of dynamic properties for standalone structural health 
monitoring systems," Mechanical Systems and Signal Processing, vol. 25, no. 8, pp. 3010-3026, 2011.

[141] R.-J. Wang and D.-G. Shang, "Fatigue life prediction based on natural frequency changes for spot welds under random loading," International Journal of Fatigue, vol. 31, no. 2, pp. 361366, 2009.

[142] Y. J. Yan, L. Cheng, Z. Y. Wu, and L. H. Yam, "Development in vibration-based structural damage detection technique," Mechanical Systems and Signal Processing, vol. 21, no. 5, pp. 2198-2211, 2007. 

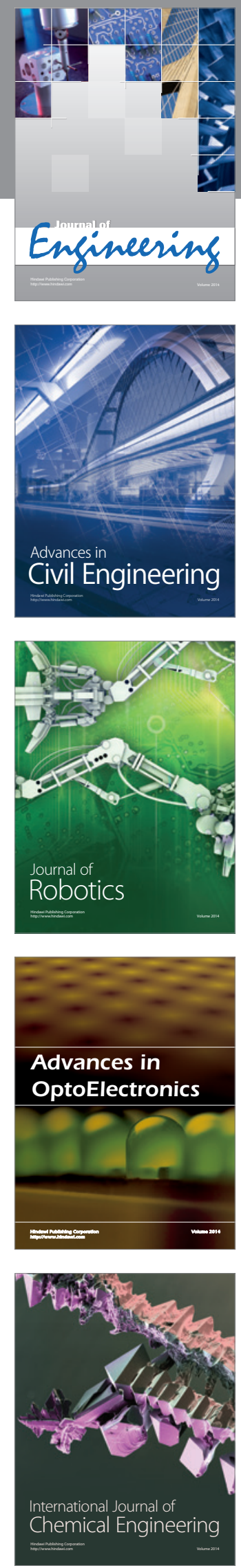

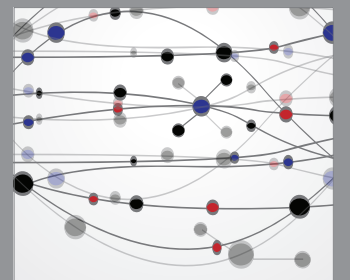

The Scientific World Journal
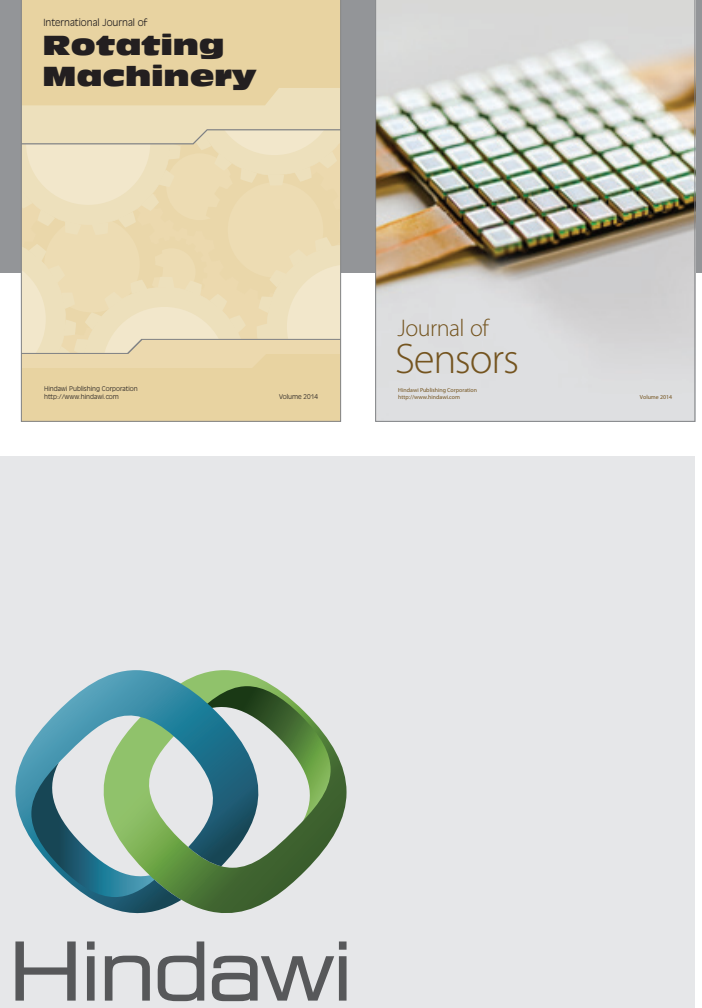

Submit your manuscripts at http://www.hindawi.com
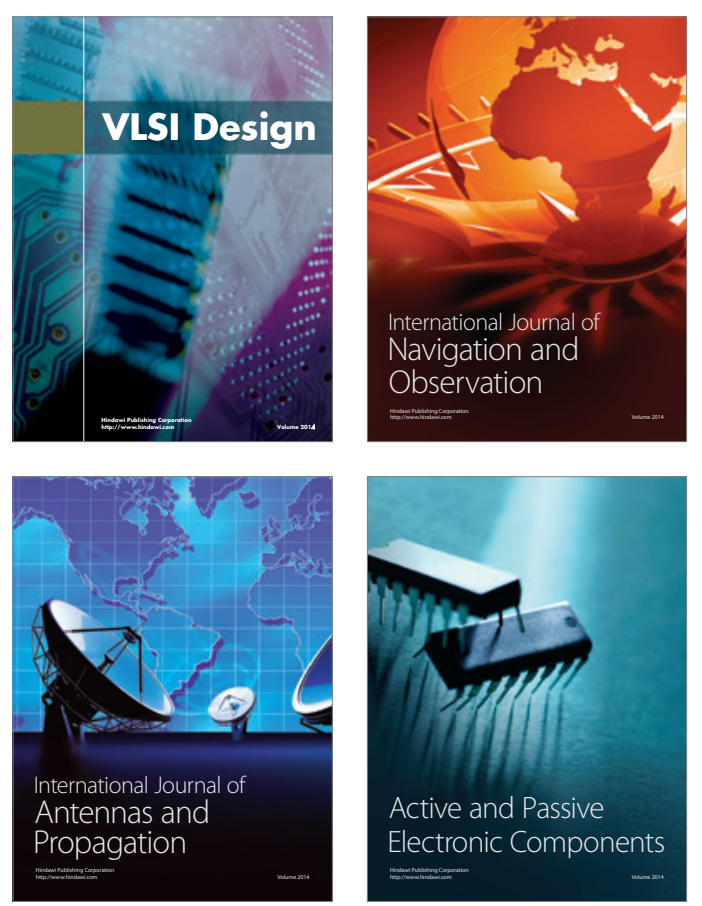
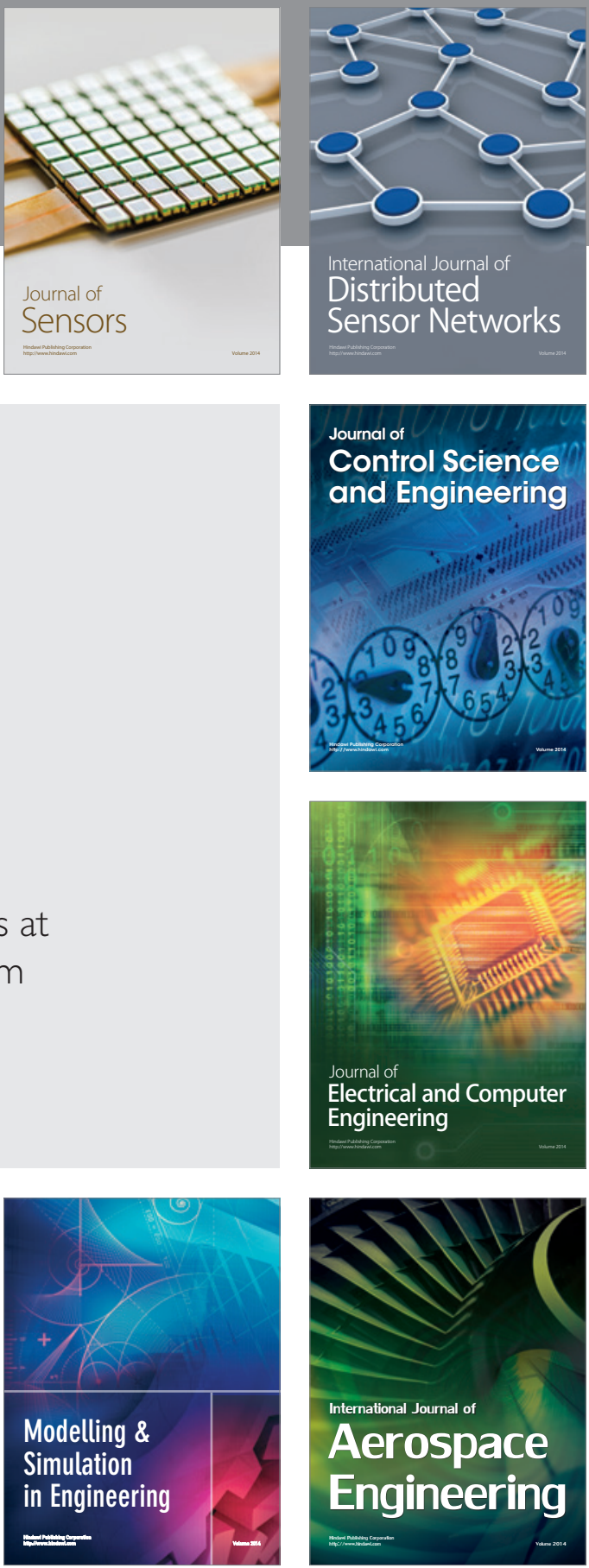

Journal of

Control Science

and Engineering
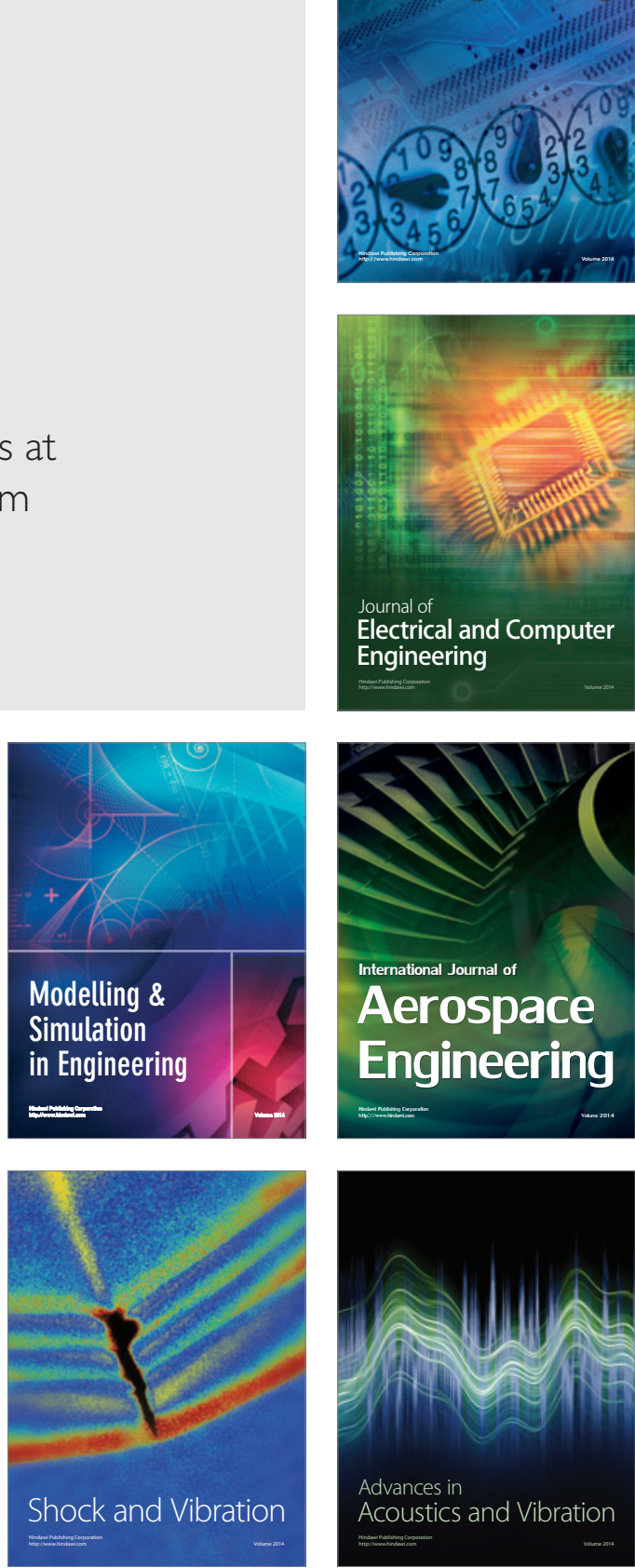